\title{
Technology vs Ideology: How Far will Artificial Intelligence and Distributed Ledger Technology Transform Corporate Governance and Business?
}

\author{
Iris H-Y Chiu* and Ernest WK Lim**
}

\section{Introduction}

Disruptive technologies look set to introduce marked changes to the corporate world. VITAL, a robot programmed with artificial intelligence, has been appointed as a voting director to the Board of a Hong Kong venture capital company, ${ }^{1}$ and a number of stock exchanges are encouraging listed companies to adopt distributed ledger technology to conduct annual general meetings between their boards and shareholders. ${ }^{2}$

Artificial Intelligence ('Al') and distributed ledger technology ('DLT') are referred to as the new 'Corporate Technologies' or 'CorpTech'3 , currently watched in terms of their potential for change. Specifically, we are watching for the extent to which the organisation, structures and processes, and institutions of economic life, especially those under the aegises of corporations, would shift in response to the advent of Al and DLT. We also need to consider if such shifts warrant responses from the law. We discuss Al and DLT as different domains of technological advancements but they also interface at certain points. The different treatment we give to Al and DLT is essential as their impact on change is different. However, as we will engage in theoretical treatment of how technological change impacts institutions and corporate law more generally, we refer to 'CorpTech' as an umbrella term where relevant.

We make two distinct but interrelated contributions to the literature on CorpTech. First, we advance an analytic framework, which we term as 'incremental/facilitative', 'radical/disruptive' and 'fundamental/structural', to promote a nuanced understanding of the development of AI and DLT and their effects on business processes, organisation and management, particularly on corporate governance. Second, we develop a theory of how CorpTech will shape corporate law and governance by examining the drivers for institutional change combined with the drivers for corporate law and governance. We argue that CorpTech is unlikely to radically alter the power structures and incentive mechanisms of shareholders, directors and managers, and hence, any fundamental/structural changes to corporate governance is not likely in the near future.

Regarding our first contribution, the existing literature has speculated on the impact of CorpTech on business practices in general, and corporate governance in particular, but there appears to be no framework for analysis. Our three level framework fills this gap by distilling the key features of technological change in order to map onto legal/ideological relevance, for the purpose of informing law and policy thinking.

\footnotetext{
*Professor of Corporate Law and Financial Regulation, University College London (UCL).

**Associate Professor of Law, National University of Singapore.

We are thankful to the research assistance of Sathya Kumar. All errors and omissions are ours.

${ }^{1}$ Rob Wile, 'A Venture Capital Firm Just Named an Algorithm to its Board of Directors' (14 May 2014) at www.businessinsider.com.au/money-markets.

${ }^{2}$ Christoph van der Elst and Anne LaFarre, 'Blockchain and Smart Contracting for the Shareholder Community' (2019) 20 European Business Organisations and Law Review 111; 'ICJ and Broadridge Execute the First Blockchain-based Interoperable Proxy Voting Process in Japan' (14 Jan 2019), 'Santander uses blockchain for investors' vote' (Financial Times 21 May 2018); 'NSE to Test E-voting Using Blockchain' (Express Computer, 27 Sep 2018) on the Indian Stock Exchange's rollout of e-voting for listed companies' general meetings. ${ }^{3}$ Luca Enriques and Dirk Zetzsche, 'Corporate Technologies and the Tech Nirvana Fallacy' (2019) at http://ssrn.com/abstract_id=3392321.
} 
The first level, 'incremental/facilitative' means that technological change largely facilitates wellaccepted business purposes such as growth, cost-saving and other efficiencies. Even if the magnitude of change is pronounced, such as the replacement of job roles in the business, there is a primarily economic driver and rationality that underpin such change. On this view, incremental/facilitative change does not challenge the ideology underlying the economic structures and corporate organizations in the US and UK, namely the free market economy and shareholder primacy. ${ }^{4}$

At the second level, 'radical/disruptive' change, in our view, begins as a 'challenger' and attains a 'substitutive' character. This is drawn from Bower and Christensen's analysis of 'disruptive innovation' in product markets. 'Disruptive innovation' refers to the creation of new markets and value networks that eventually disrupt existing markets and value networks, displacing established market leaders and alliances. This framework may be more specifically understood as the development of innovation that first takes place at the low end of the market and does not immediately threaten incumbents as it is a weak substitute. The innovation, however, distinguishes itself by offering new performance criteria to the market, such as convenience and portability, lower price, or ease of use. The gradual uptake by the market and development of economies of scale steadily allows for the innovation to become dominant in due course, disrupting and replacing incumbents. In later literature, commentators have sought to broaden the concept of 'disruptive innovation' ${ }^{6}$ This is because some innovations produce disruption by introducing novelty and displacing incumbents in different ways but reach the same result. ${ }^{7}$

In this manner, we characterise 'radical/disruptive' change as a marked manner of change in organising/conducting economic life where such change develops from an emerging 'new way of doing things' to a challenger and substitute for the conventional 'way of doing things'. We also regard radical/disruptive change as likely to give rise to questions regarding institutional or paradigm change, i.e. whether existing institutions in the law cater for such a change, and whether existing paradigms have shifted/need to shift in response. For example, if the appointment of a voting robot as director on a Board becomes the norm in industry practice, such a change gives rise to questions as to the status of such a robot director in relation to its human counterparts and the status of its vote. These questions would be of a policy nature as choosing to regard robot directors on par with human directors would give rise to issues such as how legal personality and liability should be structured, and choosing not to would give rise to questions of attribution of agency and liability instead..$^{8}$ In sum, radical/disruptive change ultimately provokes thinking into policy change, impacting legal and regulatory institutions.

\footnotetext{
4 Andrew Keay, 'Shareholder Primacy in Corporate Law: Can it Survive? Should it Survive?' (2010) 7 European Company and Financial Law Review 369. At the global level, shareholder primacy is argued to be the dominant model of the corporate economy, Henry Hansmann and Reiner Kraakman, 'The End of History for Corporate Law' (2000) 89 Georgetown Law Journal 439.

5 Joseph Bower and Clayton Christensen, 'Disruptive Technologies: Catching the Wave' (1995) Harvard Business Review 43-53; Clayton Christensen and Michael Raynor, The Innovator's Solution (Harvard Business School Press, 2003).

${ }^{6}$ By not confining to developments in the same sector, to that necessarily starting at the low end of the market or that adopting a gradual trajectory of displacement.

7 Larry Downes and Paul Nunes, 'Big Bang Disruption' (March 2013) Harvard Business Law Review 45; David Ahlstrom, 'Innovation and Growth: How Business Contributes to Society' (2010) 24 Academy of Management Perspectives 11.

${ }^{8}$ Robert van den Hoven van Genderen, 'Legal Personhood in the Age of Artificially Intelligent Robots' in Woodrow Barfield and Ugo Pagallo (eds), Research Handbook on the Law of Artificial Intelligence (Cheltenham:
} 
Finally, we introduce the third level of our framework, 'fundamental/structural' change, which refers to completely new and 'eradicative' ways of organising or conducting economic life, such that conventional structures and institutions become largely replaced, much like how urbanisation replaces and therefore eradicates old rural ways of life in a geographical area. Commentators' discussion of Board replacement (human by Al) ${ }^{9}$ or the advent of 'platform governance' ${ }^{10}$ are examples of such fundamental/structural changes as the conventional organisation and conduct of economic life could be rendered largely unrecognisable. Such nature of change necessitates rethinking in terms of ideology and paradigms for the organisation and institutions of economic life, and will profoundly impact corporate law and governance.

After providing a critical overview of Al and DLT and their effect on business practices and corporate governance through this three-level framework, our second contribution is to demonstrate that the major power groups influencing corporate law and governance norms are likely to mobilize old ideology with technological spins in order to achieve incremental institutional changes aligned with their incentives and interests. We suggest it would be unlikely that institutional change would be achieved to facilitate radical/disruptive or fundamental/structural changes to the extent that it denudes extant power structures of their power. To make this argument, we first explore the key theoretical drivers of institutional change. Subsequently, we explain how these drivers are connected to the theoretical drivers for changes in corporate law and governance, specifically the role of shareholders and directors/managers within the context of different economic systems and ownership structures. Finally, we apply this combined theoretical framework to the three-level framework of technological change we discussed. We predict that directors and shareholders will embrace incremental/facilitative Al and DLT to render the board and general meeting decisionmaking process more efficient and effective. Al is, however, unlikely to fully replace directors or managers, let alone companies, in the foreseeable future. Thus, the idea of self-driving companies is unlikely to become a mainstream economic phenomenon. We are also doubtful that DLT will result in full disintermediation as powerful corporate organs will prefer to manage and subsume its use to be compatible with their incentives and preferences.

The management of institutional change by social mediation and influential groups will not simply be resistance or marginalisation of technological change. This is because commercial entities are lured by the efficiencies of innovation while incentivised to maintain power and control over how change affects them. Hence, there would likely be a convergence amongst economic actors, society and policy-makers upon the ethical governance of Al and the efficiency governance of DLT for the future, ensuring a highly anthropocentric and managed approach to any institutional change.

The structure of this article is as follows. Section A puts forward the analytic framework of 'incremental/facilitative', 'radical/disruptive', and 'fundamental/structural' transformation by technology. Section B examines the theoretical drivers for institutional change in response to technological developments and then analyses the theoretical drivers for changes in corporate

Edward Elgar 2018) in ch8; Jans-Erik Schirmer, 'Teilrechtsfähigkeit for Autonomous Systems: Introducing a 'Halfway' Status' (2018) at https://www.rewi.hu-berlin.de/de/If/Is/bcm/team/jan-erik-schirmer/publikationenund-vortraege/Schirmer RegulatingAl Teilrechtsfaehigkeit.pdf, and more to be discussed later.

${ }^{9}$ For example, Martin Petrin, 'Corporate Management in the Age of Al' (2019) Columbia Business Law Review (forthcoming).

${ }^{10}$ Mark Fenwick and Erik PM Vermeulen, 'Technology and Corporate Governance: Blockchain, Crypto, and Artificial Intelligence' (2018) at http://ssrn.com/abstract id=3263222; Mark Fenwick, Joseph A McCahery and Erik PM Vermeulen, 'The End of Corporate Governance: Hello Platform Governance' (2018) at http://ssrn.com/abstract_id=3232663. 
governance. Section $\mathrm{C}$ applies the combined insights from both institutional and corporate governance theories to the three level framework. Section $D$ makes three predictions on the extent of institutional change, at least in the foreseeable future, and concludes that institutional change will be incremental, with futuristic visions such as the replacement of the Board in full or the complete overhaul of enfranchisement in corporate governance not likely to occur except in small and experimental situations. Complete reconfiguration would not be easily wrought, as there would certainly be an ideological struggle. Although it may be relatively easy to see business process changes such as in customer service chatbots ${ }^{11}$ and supply chain management, ${ }^{12}$ the advent of a decentralised 'prosumer' economy where mass production under the aegis of corporations is no longer the norm, ${ }^{13}$ is yet far.

The advent of $\mathrm{Al}$ is challenged by social and political questions regarding the relevance of human agency, from the lowest skilled right up to the Boardroom, and DLT powers the rise of bottom-up enterprise and an alternative economic ethos while corporatisation and corporate globalisation are buffeted by social and political headwinds. ${ }^{14}$ The result cannot be functionally determined. We argue that the inexorable logic and pace of Al and DLT will only be mediated and moderated within an institutional paradigm, within which our theoretically-informed three-level framework sits.

\section{A. Three Levels of Change Wrought by 'CorpTech'}

This Section first provides a narrative regarding the types of change brought about by CorpTech. We provide a short primer on the rise of AI and DLT in business and corporate processes before providing accounts of the three different types of change that Al and DLT would bring respectively. These accounts are then followed by reflective sections on their implications for current legal institutions and policy choices. Distilling the implications does not mean that policy choices have to be made in favour of reform, as mapping out such implications provides us only with navigational routes. The choice of particular routes is argued in this paper to be based on a multi-faceted institutional theory that is explored in Section B.

\section{A Short Primer on Al and its Development}

Scientific research and development of Al can be traced back to the 1950s, when the pinnacle achievement for Al was stipulated to be the passing of the Turing test. ${ }^{15}$ Alan Turing stipulated that if a human and machine were in conversation in different physical locations where the human cannot see the machine, the machine would pass the Turing test of being intelligent, on par with humans, if the human could not tell clearly $30 \%$ of the time whether it was a machine or human on the other

\footnotetext{
${ }^{11}$ Andreas Kaplan and Michael Haenlein, 'Siri, Siri, In My Hand: Who's the Fairest in the Land? On the Interpretations, Illustrations, and Implications of Artificial Intelligence' (2019) 62 Business Horizons 15.

${ }^{12}$ Above; Adam Sulkowski, "Blockchain, Business Supply Chains, Sustainability, and Law: The Future of Governance, Legal Frameworks, and Lawyers" (2019) 43:2 Del J Corp L 303; Jan Mendling et al, 'Blockchains for Business Process Management - Challenges and Opportunities' (2018) 9 ACM Transactions on Management Information Systems 4.

${ }^{13}$ Vatravslav Zovko, 'Management in the Year 2050' (2018) 16 Interdisciplinary Description of Complex Systems 417.

${ }^{14}$ Joel Bakan, The Corporation: The Pathological Pursuit of Profit and Power (Robinson Publishing 2005) is an account of irresponsible practices of the global multinational corporation.

${ }^{15}$ Alan M. Turing, 'Computing Machinery and Intelligence' (1950) 59 MIND 433; 'What is the Turing Test?' (The Guardian, 9 June 2014) at https://www.theguardian.com/technology/2014/jun/09/what-is-the-alan-turingtest.
} 
side after five minutes of conversation. ${ }^{16}$ The elusive achievement by computers in relation to this standard to date shows that 'super intelligence' ${ }^{17}$ the term used to describe Al that is able to replicate human intelligence, is still some way away. The development of $A l$ is often discussed in three stages, i.e. narrow Al, general Al and ultimately, super Al.

Narrow Al refers to the ability of computers to undertake specific tasks, such as making astronomical calculations, operating a self-service drink vending machine and learning the rules of a game such as chess in order to play it. ${ }^{18}$ Narrow Al has developed from being programmed with rules, sometimes complex rules, and the execution of those rules in a systematic, consistent and impeccable manner, to machine learning, which is a more advanced form of narrow Al. Machine learning takes narrow $\mathrm{Al}$ into the next step as the machine is trained to be able to devise the rules needed for it to achieve the outcomes predefined by its designer. Machine learning takes place by feeding the machine voluminous amounts of relevant data matched with outcomes, in order for it to recognise patterns. ${ }^{19}$ A machine is therefore able to devise more than one route of pattern recognition in order to achieve outcomes, surpassing the programmed robot that needs to be fed with the relevant sets of rules. ${ }^{20}$ Machine learning is being refined at a dynamic pace, as recent research exposed at conference proceedings shows how decision trees have been refined to make pattern recognition ${ }^{21}$ more accurate and precise through the employment of sophisticated linguistic, statistical and probabilistic methods such as artificial neural networks, ${ }^{22}$ natural language processing, ${ }^{23}$ fuzzy logic, ${ }^{24}$ rough set

\footnotetext{
${ }^{16}$ So far only one computer program that simulates a 13 year old Ukrainian boy developed by the University of Reading has passed the Turing test run in the Royal Society of London in 2014, see 'Computer AI Passes Turing Test in World First' (BBC News, 9 June 2014), at https://www.bbc.co.uk/news/technology-27762088.

${ }^{17}$ Kaplan and Haenlein (2019).

${ }^{18} \mathrm{~L}$ Thorne-McCarty, 'Finding the Right Balance in Artificial Intelligence and the Law' in Woodrow Barfield and Ugo Pagallo (eds), Research Handbook on the Law of Artificial Intelligence (Cheltenham: Edward Elgar 2018) in ch 3.

${ }^{19}$ Yanqing Duan, John S. Edwards, Yogesh K Dwivedi, 'Artificial Intelligence for Decision Making in the Era of Big Data - Evolution, Challenges and Research Agenda' (2019) 48 International Journal of Information Management 63.

${ }^{20}$ Literature on machine learning shows progress in 'automated learning' and execution of strategies as machines are trained with data and patterns. However, highly unpredictable outcomes still persist as machines do not learn by reasoning like humans and their decision-making can be highly inappropriate at times. Gillian Hadfield, 'Rules for Robots: Building Legal Infrastructure for Artificial Intelligence', CEL Biennial lecture, University College London, 18 June 2019; Arno Lodder, 'Regulation of Algorithms', lecture at the London School of Economics, 19 June 2019.

${ }^{21}$ Aljaaf et al (2014); Zeeshan Ali Rana, Mian M. Awais, and Shafay Shamail, 'Impact of Using Information Gain in Software Defect Prediction Models' in De-Shuang Huang, Vitoantonio Bevilacqua and Prashan Premaratne (eds), Intelligent Computing Theory (Heidelberg: Springer 2014) at 637-647 on techniques to mitigate errors in refining the decision tree.

${ }^{22}$ Ahmed J. Aljaaf, Dhiya Al-Jumeily, Abir J. Hussain, David Lamb, Mohammed Al-Jumaily, and Khaled AbdelAziz, 'A Study of Data Classification and Selection Techniques for Medical Decision Support Systems' in DeShuang Huang, Kang-Hyun Jo and Ling Wang (eds), Intelligent Computing Methodologies (Heidelberg: Springer 2014) at 135-143; Mohammed Abbas Kadhim, M. Afshar Alam, and Harleen Kaur, 'A Multi-Intelligent Agent for Knowledge Discovery in Database (MIAKDD): Cooperative Approach with Domain Expert for Rules Extraction' in De-Shuang Huang, Kang-Hyun Jo and Ling Wang (eds), Intelligent Computing Methodologies (Heidelberg: Springer 2014) at 602-614.

${ }^{23}$ Paulius Cerka , Jurgita Grigien, Gintare Sirbikyt, 'Liability for Damages Caused by Artificial Intelligence' (2015) 31 Computer Law and Security Review 316.

${ }^{24}$ Aljaaf et al (2014), above; Kadhim et al (2014).
} 
theory ${ }^{25}$ and the use of expert systems. ${ }^{26}$ Some rather astounding machine learning has been unveiled to the world in relation to playing computer games, ${ }^{27}$ oncological diagnosis ${ }^{28}$ and automatic evaluations of various situations, such as student learning in a virtual environment, ${ }^{29}$ helping an online customer (assisted by chatbots), ${ }^{30}$ and credit scoring for financial institution lending decisions. ${ }^{31}$ Machine learning therefore automates certain evaluative processes that may have exclusively relied on human judgment before, achieving various benefits such as greater accuracy of outcomes and wider and speedier access to certain services.

Fundamentally, the deployment of Al changes the structure of human agency. Narrow Al is often described as able to free the need for human agency in repetitive and choresome tasks, such as by replacing the many supermarket checkout lanes with self-service machines. ${ }^{32}$ Increasingly, the use of chatbots and automated lending or investment services ${ }^{33}$ may be seen to be for the purpose of keeping a business open $24 / 7$, promoting access without the need for human customer service agents to be around, and therefore facilitating access in a more cost-effective manner. Such use is aimed at supplementing human resource capacity. Robots such as IBM's Watson ${ }^{34}$ provide facilitative support for complex decisions where many factors and dense volume of information need to be considered by an expert human or a group. Bounded rationality on the part of human beings means that human imperfections could render a decision inaccurate, and the help of logical processing by a machine can act as a useful check on an otherwise exclusively human judgment. Looking at narrow Al in this manner does not mean that human agency is necessarily inferior or replaceable in relation to the same tasks. ${ }^{35}$ The increasing sophistication of narrow Al means that human agency changes would come about, ${ }^{36}$ and the ground for contest is crucially over the humanmachine mix in relation to tasks and who determines the mix as a matter of policy. ${ }^{37}$ At a more

\footnotetext{
${ }^{25}$ Fu Hsiang Chen, Der-Jang Chi, and Chun-Yi Kuo, 'Using Rough Set Theory and Decision Trees to Diagnose Enterprise Distress - Consideration of Corporate Governance Variables' in De-Shuang Huang, Kang-Hyun Jo and Ling Wang (eds), Intelligent Computing Methodologies (Heidelberg: Springer 2014) at 199-209.

${ }^{26}$ Kadhim et al (2014).

${ }^{27}$ For example, Al bots have achieved significant success in defeating human player teams at Quake III Arena, see 'An Al Taught itself to Play a Video Game- for the first time it is beating humans' (The Conversation, 2019). ${ }^{28}$ IBM's Watson is a super-computer designed to assist in oncological diagnosis and development of personalised patient care, see www.ibm.com/watson-health.

${ }^{29}$ Michelle L. F. Cheong, Jean Y.-C. Chen, and Bing Tian Dai, 'An Intelligent Platform with Automatic Assessment and Engagement Features for Active Online Discussions' in Franz Wotawa, Gerhard Friedrich, Ingo Pill, Roxane Koitz-Hristov and Moonis Ali (eds), Advances and Trends in Artificial Intelligence. From Theory to Practice (Heidelberg: Springer 2019) at 730-743; and earlier development in evaluating 'chat quality' see Zhenyu Wu, Yu Liu, Deyi Li, and Yan Zhuang, 'Quantifying the Evolutions of Social Interactions' in De-Shuang Huang, Vitoantonio Bevilacqua and Prashan Premaratne (eds), Intelligent Computing Theory (Heidelberg: Springer 2014) at 162-172.

${ }^{30}$ Kaplan and Haenlein (2019).

31 'Fujitsu takes on Fintech by Developing Credit Scoring Tool for Banks' (26 August 2019) at https://asia.nikkei.com/Business/Technology/Fujitsu-takes-on-fintech-with-Al-credit-scoring-tool-for-banks.

${ }^{32}$ Discussed in 'Artificial Intelligence and the Impact on the Company Secretary' (CSSA, Sep 2018).

${ }^{33}$ Such as robo-advice, discussed in Iris H-Y Chiu, 'Transforming the Financial Advice Market - The Roles of Robo-advice, Financial Regulation and Public Governance in the UK' (2019) Banking and Finance Law Review, forthcoming and citations within.

${ }^{34} \mathrm{~N} 28$ above, but doctors experimented with it and the recommendations it yielded were sometimes regarded as unsafe, see 'IBM's Watson Gave Unsafe Recommendations for Treating Cancer' (26 July 2018) at https://theverge.com/2018/7/26/17619382/ibms-watson-cancer-ai-healthcare-science.

${ }^{35}$ Barry Eichengreen, 'Two Myths About Automation' (Barron's, 18 Dec 2017).

${ }^{36}$ Humans can be deployed into more purposeful work, such as managing the new dynamics between humans and robots, Kathleen and Ralph Wilburn, 'Challenges for Managing Business with $21^{\text {st }}$ Century Technology' (2018) 9 Review of Business and Finance Studies 13.

${ }^{37}$ Eichengreen (2017).
} 
advanced level, research and development is underway on 'General Al'. General Al is more ambitious as it relates to machines with more 'holistic' or integrated capacity, simulating human reasoning that is more multi-faceted in nature. ${ }^{38}$ Recent research exposed in conference proceedings show that there is only incremental development towards building general $\mathrm{Al} .{ }^{39} \mathrm{As}$ the developments in communications robotics show, ${ }^{40}$ general Al seems to be rudimentary, and may be based on machine learning for expanded purposes. ${ }^{41} \mathrm{An}$ area of much-hyped development in general $\mathrm{Al}$ is that of self-driving cars, ${ }^{42}$ as self-driving essentially encompasses a number of different functions that taken together, constitute the act of 'driving' or being in control of a motor vehicle. General Al that is able to achieve complex and composite tasks attains a form of human resemblance, posing a greater challenge to the nature of human agency than narrow Al. What is required of human agency in economic life could change markedly, impacting how education and training should be reconfigured. However, in developing such general Al, a plethora of errors and hazards would have to be dealt with, such as the fatalities that have been caused by self-driving cars. ${ }^{43}$ Hence, where the line of judgment would lie for general Al to be deployed in a mainstream

\footnotetext{
${ }^{38}$ Human reasoning is often based on an integration of rationality, memory, contextual knowledge and behavioural shortcuts or heuristics, as well as communal, not individualistic factors such as social conditioning, Philip N Johnson-Laird, 'Mental Models and Human Reasoning' (2010) 107 PNAS 18203 at https://doi.org/10.1073/pnas.1012933107. The holistic and integrated nature of human reasoning is distinguished from Al whose processing is inevitably linear in its logic, Lodder (2019).

${ }^{39}$ It is painfully challenging to teach Al to learn a new language, Alex Glushchenko, Andres Suarez, Anton Kolonin, Ben Goertzel, Claudia Castillo, Man Hin Leung and Oleg Baskov, 'Unsupervised Language Learning in OpenCog' in Matthew Iklé, Arthur Franz, Rafal Rzepka and Ben Goertzel (eds), Artificial General Intelligence (2018) at 109-118. However, there may be more significant breakthrough in enabling Als to design, see Andreas M. Hein and H'el'ene Condat, 'Can Machines Design? An Artificial General Intelligence Approach' in Matthew Iklé, Arthur Franz, Rafal Rzepka and Ben Goertzel (eds), Artificial General Intelligence (2018) at 87-99. ${ }^{40}$ Kotaro Hayashi, Takayuki Kanda, Hiroshi Ishiguro, Tsukasa Ogasawara, and Norihiro Hagita, 'An Experimental Study of the Use of Multiple Humanoid Robots as a Social Communication Medium' in Constantine Stephanides (ed), Universal Access in Human-Computer Interaction (Heidelberg: Springer 2011) at 32-41 on Al mastering passive but not interactive conversation. Learning in communications is slowly based on simulation of human gestures and behaviour, Masahide Yuasa and Naoki Mukawa, 'Building of Turn-Taking Avatars that Express Utterance Attitudes: A Social Scientific Approach to Behavioral Design of Conversational Agents' in Constantine Stephanides (ed), Universal Access in Human-Computer Interaction (Heidelberg: Springer 2011) at 101-107.

${ }^{41}$ On techniques in reducing errors, see Mark Wernsdorfer, 'How Failure Facilitates Success' in Matthew Iklé, Arthur Franz, Rafal Rzepka and Ben Goertzel (eds), Artificial General Intelligence (2018) at 292-302 or stimulating broader, contextual considerations or lateral thinking, see Kristinn R. Th'orisson and Arthur Talbot, 'Cumulative Learning with Causal-Relational Models' in in Matthew Iklé, Arthur Franz, Rafal Rzepka and Ben Goertzel (eds), Artificial General Intelligence (2018) at 227-237; Rafik Hadfi, 'Solving Tree Problems with Category Theory' in Matthew Iklé, Arthur Franz, Rafal Rzepka and Ben Goertzel (eds), Artificial General Intelligence (2018) at 62-76.

${ }^{42}$ For example Google's subsidiary Waymo has launched a small self-driving taxi fleet in Phoenix, Arizona, see 'Waymo Launches First US Commercial Self-driving Taxi Service' (5 Dec 2018) at https://www.independent.co.uk/life-style/gadgets-and-tech/news/waymo-self-driving-taxi-service-googlealphabet-uber-robotaxi-launch-us-a8669466.html.

43 'Uber's Fatal Self-Driving Crash' (May 2019) at https://www.theverge.com/2018/3/28/17174636/uber-selfdriving-crash-fatal-arizona-update; 'Tesla's Model 3 autopilot mode was activated seconds before a fatal crash' (17 May 2019) at https://www.technologyreview.com/f/613549/teslas-model-3-autopilot-mode-wasactivated-seconds-before-a-fatal-crash/.
} 
manner is highly uncertain- would it be a risk-based judgment, ${ }^{44}$ or would it be precautionary in nature? ${ }^{45}$

Until such policy choices can be resolved, it is uncertain how general Al can develop into super Al by 2045 , the year that Kurzweil has famously declared would be marked by the supplanting of humans by robots. ${ }^{46}$ Super Al refers to $\mathrm{Al}$ that is indistinguishable from human sentience and capacity, presumably passing the Turing test with ease. Again, fiction provides us with a glimpse of what super Al looks like, in the form of Ava in Ex Machina ${ }^{47}$ or a more benign version in Japanese animation Time of Eve ${ }^{48}$. Super Al and humans would live side by side and would be almost indistinguishable except for the laws of robotics that govern android behaviour, such laws safeguarding the superiority of humans. As fiction uncannily shows, developments towards super Al would necessarily be underpinned by policy choices involving law, governance, ethics, and social considerations such as inclusion and cohesion. This primer sets out a brief context for the ultimate importance of the institutional paradigms within which technological change would be navigated.

\section{A Short Primer on DLT and its Development}

DLT was first introduced as part of the innovation for bitcoin, the cryptocurrency touted to offer an alternative private currency to sovereign-backed fiat currencies. ${ }^{49}$ The bitcoin blockchain was first developed to solve the Byzantine Generals Coordination Problem which relates to how consensus or concerted action can be attained despite a lack of trust amongst actors. This is necessary so that a network can be built up for the credible adoption of the new private currency at scale without the tyranny of centralised control or power. Bitcoin would be created, transferred and recorded on a blockchain, a ledger sustained by a network of participants (nodes). Nodes collectively have the responsibility to maintain the credibility of the ledger by preventing double spending, but this is achieved by individual and uncoordinated efforts. Nodes are supposed to verify blocks of transaction information and then irreversibly add these verified blocks to the chain, forming a complete and immutable record for the entire network. Nodes are incentivised to verify by being rewarded with the native currency of the chain, ${ }^{50}$ and can be carried out by proof-of-work. ${ }^{51}$ In this manner, although the network is decentralised, the work of verifiers, which is called 'mining', ensures the alignment of individual incentives of participants with the collective good of the network. ${ }^{52}$

\footnotetext{
${ }^{44}$ Meaning that judgment for permissive or regulative policies is likely to be based on an assessment of risk and the costs and benefits of introducing governance or regulation, Christopher Hood, Henry Rothstein, and Robert Baldwin, The Government of Risk: Understanding Risk Regulation Regimes (Oxford: OUP 2001).

${ }^{45}$ May be invoked on the basis of scientifically evaluated potential harm, see EU guidance on such regulation in relation to environmental protection, at https://eur-lex.europa.eu/legalcontent/EN/TXT/?uri=LEGISSUM\%3AI32042.

${ }^{46}$ Ray Kurzweil, The Singularity Is Near: When Humans Transcend Biology (Duckworth 2005).

47 Film released in 2014.

${ }^{48}$ Released in 2010. The laws of robotics are commonly derived from Issac Asimov, Three Laws of Robotics, see http://webhome.auburn.edu/ vestmon/robotics.html.

${ }^{49}$ Satoshi Nakamoto, 'Bitcoin: A Peer to Peer Electronic Cash System' (2008) at https://bitcoin.org/bitcoin.pdf.

${ }^{50}$ A process known as 'mining'.

${ }^{51}$ Proof of work involves solving a cryptographic puzzle to identify matching hashes unique to the transaction and then broadcasting this work to gain consensual support in the network. Other forms of verification protocols have since been developed for other blockchains, such as proof-of-stake, involving validators staking a certain sum of their cryptocurrency in order to verify transactions. See 'Proof of Work vs Proof of Stake' at https://blockgeeks.com/guides/proof-of-work-vs-proof-of-stake/.

52 The distributed ledger is a concept whereby all nodes maintain the same copy of transactions and last-done status of the ledger, so that all records are immutable, indelible and cannot be arbitrarily adjusted. This is
} 
The development of the ethereum blockchain ${ }^{53}$ is the next significant and crucial step for the revolutionising potential of DLT. The ethereum blockchain is an infrastructural blockchain which can support a variety of economic activity more complex than the initially dominant activity of payment transfer. It allows smart contracts ${ }^{54}$ to be coded and executed on the ledger to exchange data, execute transactions and record transfers and balances. The ethereum blockchain has inspired newer innovations such as Tezos, EON and Tron, all offering protocol or 'infrastructural' layers for smart contract-based business applications to be constructed on top of them. New business applications can be developed for new enterprises that sell virtual goods such as 'crypto-kitties' ${ }^{.5}$ Blockchain-based business models provide peer-to-peer platforms for direct transactions in new forms of commodification, ${ }^{56}$ creating new markets for novel goods or services. In another example, peer-to-peer energy trading platforms disrupt and challenge existing oligopolistic markets in energy.$^{57}$ lungo provides a disintermediated platform that links up individual wifi services to form a global wireless internet network; ${ }^{58}$ Golem has a business model that allows access to individual computers' idle power for a fee ${ }^{59}$ and brings together a network of computers willing to share their 'excess capacities'. Blockchain-based businesses are a step beyond the platform economy, ${ }^{60}$ which has brought about new business models and markets that seek to be alternatives to the corporate economy of centralised mass production and distribution. Decentralising technologies offer opportunities for flattening economic structures, ${ }^{61}$ galvanising new economic actorhood, activity and creation of wealth, and weakening the stranglehold by corporate economies on access to economic opportunities.

The development of new blockchain-based businesses has given rise to the 'initial coin offering' (ICO) movement. ${ }^{62}$ In order to fund blockchain-based development projects, developers typically offer 'tokens' in return for cryptocurrency such as bitcoin or ether from supporters of the project.

described as 'trustless trust' but see limitations discussed in Kevin Werbach, 'Trust, But Verify: Why the Blockchain Needs the Law' (2018) 33 Berkeley Tech. L.J. 489 (2018).

${ }^{53}$ See https://www.coindesk.com/information/who-created-ethereum.

${ }^{54}$ These are pieces of code or algorithms designed to execute certain commands if certain conditions are met, resulting in the execution or formation of legal obligations, hence 'smart contracts', see Nick Szabo, 'Smart Contracts: Building Blocks for Digital Markets', University of Amsterdam (1996),

http://www.fon.hum.uva.nl/rob/Courses/InformationInSpeech/CDROM/Literature/LOTwinterschool2006/szab o.best.vwh.net/smart_contracts_2.html, and layman's version at

https://www.coindesk.com/information/ethereum-smart-contracts-work.

${ }^{55}$ https://www.cryptokitties.co.

${ }^{56}$ The trend of new commodification that has been made possible by digitalisation is discussed in Miriam Cherry, 'Cyber Commodification' (2013) 72 Maryland Law Review 381.

${ }^{57}$ Competition in the energy sector, such as in the UK has long been a challenging issue, see for example, Competition in the UK's Electricity Market (2016) at https://assets.publishing.service.gov.uk/government/uploads/system/uploads/attachment data/file/556310/ Electricity competition.pdf showing that entrenched players (the Big 6 companies) continue to take over $80 \%$ of market share although new and smaller players are challenging such a trend gradually.

58 https://iungo.network/.

59 See https://golem.network/.

60 Martin Kenney and John Zysman, 'The Rise of the Platform Economy' (2016) Issues in Science and Technology 61 which sees digital platforms as offering new business models, at https://www.nbp.pl/badania/seminaria/25x2016_2.pdf.

${ }^{61}$ Thomas L Friedman, The World is Flat (Farrar, Straus and Giroux 2005); Gillian Hadfield, Rules for a Flat World (Oxford: OUP 2016).

62 There is a lot of literature mapping the universe of ICOs, see S Adhami et al, 'Why do Businesses Go Crypto? An Empirical Analysis of Initial Coin Offerings' (2018) 100 Journal of Economics and Business 64; Dirk Zetzsche et al, 'The ICO Gold Rush: It's a Scam, it's a Bubble, it's a Super Challenge for Regulators' (2017) at http://ssrn.com/abstract=3072298. 
These tokens are a standardised piece of code embodying an entitlement to future goods or services that would be generated in the business, as well as a unit of value for future transactions on the blockchain. ${ }^{63} \mathrm{An}$ ICO therefore involves pre-selling of tokens whose use would only be realised when the business becomes live.

Further, secondary markets have arisen for people to trade their tokens even before DLT-based businesses become live. ${ }^{64}$ These tokens now have 'asset value' in secondary markets besides being functional smart contracts and units of value for the relevant blockchain-based business. The multicharacter nature of tokens is causing confusion in terms of legal and regulatory characterisation as to whether they are caught within the scope of many jurisdictions' securities and investment regulatory regimes. ${ }^{65}$ The legal grey areas of the ICO movement reflect the extent of disruption that decentralising technologies can bring to established 'ways of doing things' and the need to make policy choices in response. This continues to be an emerging area in policy determination as there is no global convergence in sight. ${ }^{66}$

Secondly, blockchain can be used to improve efficiencies and reliability in disparate recording and management systems for data, processes or networks, in both commercial and non-commercial contexts. ${ }^{67}$ In a radical case, the blockchain itself becomes the domain of management, fully decentralised and without any 'managing' authority, for predefined purposes in relation to autoexecution of smart contracts. ${ }^{68}$ However, the lack of centralised monitoring or authority can result in the usurpation of majority power in the network by rogue coordination, referred to as ' $51 \%$ attacks'. ${ }^{69}$

Reyes ${ }^{70}$ proposes that the attributes of blockchain, as a species of distributed ledger technology (DLT), are 'consensus, validity, uniqueness, immutability, and authentication'. Blockchains can bring about coordination in dispersed environments where inherent cohesion is not high. Its consensus protocols are highly logical and commensurate with incentives, and the immutable single common

\footnotetext{
${ }^{63}$ Bastien Buchwalter, 'Decrypting Cryptoassets: A Classication And Its Implications' (2019) at https://ssrn.com/abstract=3271641.

64 lbid.

65 More discussed shortly.

${ }^{66}$ More detail on the indeterminacy of the nature of tokens and regulators' responses is found in the discussion below.

${ }^{67}$ Discussed in relation to a variety of areas such as clearing and settlement, ESMA, The Distributed Ledger Technology Applied to Securities Markets (Discussion Paper, June 2016); Andrea Pinna and Wiebe Ruttenberg, 'Distributed Ledger Technologies in Securities Post-Trading' (ECB Working Paper 2016); David S Evans, 'Economic Aspects of Bitcoin and Other Decentralized Public-Ledger Currency Platforms' (2014) at http://ssrn.com/abstract=2424516, on shareholder voting see Christoph van der Elst, 'Blockchain and Smart Contracting for the Shareholder Community' (2018) at https://papers.ssrn.com/sol3/papers.cfm?abstract id=3219146. On management of supply chains, see Kari Kopela et al, 'Digital Supply Chain Transformation toward Blockchain Integration' (2017) at https://scholarspace.manoa.hawaii.edu/bitstream/10125/41666/paper0517.pdf. DLT can be used to create records in order to prevent tampering, such as in relation to food aid distribution in Africa, https://www.coindesk.com/un-food-program-to-expand-blockchain-testing-to-african-supply-chain. 68 The 'Decentralised Autonomous Organisation', a set-up for participants to pay funds into a common pool and receive tokens in return. The tokens are smart contract protocols that allow participants to vote on investment options. The smart contract protocols would allocate funds to the majority voted investment opportunity or return funds where conditions for investment are not met. See 'What is a DAO' at https://www.coindesk.com/information/what-is-a-dao-ethereum.

${ }^{69}$ More later, and see Blockchain's Once-Feared 51\% Attack Is Now Becoming Regular' (8 June 2018) at https://www.coindesk.com/blockchains-feared-51-attack-now-becoming-regular.

${ }^{70}$ Carla Reyes, 'Cryptolaw for Distributed Ledger Technologies: A Jurisprudential Framework' (2018) 58 Jurimetrics 283.
} 
record which is underpinned by authentication and validity protocols acts as the ultimate reference point. Zachariadis et al also enumerate the DLT's properties to be 'distributed, transparent, irreversible, peer-to-peer and run on computational logic' ${ }^{71}$ Organising economic activity using the DLT can lead to new configurations of economic power, as old power institutions based on hierarchy, information or roles of validation can be rendered obsolete by the force of the computational logic that applies equally to all actors and sustains all activity on the ledger. However, DLT properties can be exploited to different extent. It can be used incrementally in relation to supporting existing business or management processes, ${ }^{72}$ without fundamentally disturbing power institutions and structures.

We next turn to the different extent of CorpTech changes involving Al and DLT at the three levels of 'incremental/facilitative', 'radical/disruptive' and 'fundamental/structural'.

\section{Incremental/Facilitative Al}

In 1989, Anderson introduced an 'ESS' system to help Chief Executives of companies make fullyinformed strategic decisions and touts the system's forecasting abilities due to its integration of comprehensive amounts of information for the firm. ${ }^{73}$ Thus, why should Al be regarded as particularly novel today? The use of machine-assisted decision-making as well as automation has evolved over many decades in business and corporate processes ${ }^{74}$ Automation has been widely developed to replace repetitive and 'low-level' work. Examples include manufacturing, food/drink vending machines, automated teller machines and 24-hour supermarket checkout lanes. However, the move of Al into more executive and high levels of corporate work can be attributed to current bursts of developments in machine learning which foray into making more executive level and qualitative judgments. ${ }^{75}$

The use of machine learning in compliance-driven work, such as in preventing money laundering at banks, ${ }^{76}$ or generating compliant financial reports for securities markets ${ }^{77}$, is now observed.

However, it remains curious as to whether such machines can totally supplant legal and compliance departments. ${ }^{78} \mathrm{It}$ is reported that the corporate secretarial profession is actively embracing the

\footnotetext{
${ }^{71}$ Markos Zachariadis, Garrick Hileman, Susan V. Scott, 'Governance and Control in Distributed Ledgers: Understanding the Challenges Facing Blockchain Technology in Financial Services' (2019) 29 Information and Organisation 105.

72 See under 'Incremental/facilitative DLT'.

73 Gary Anderson, 'The ESS Revolution: Decision Support Software Reaches the Boardroom' (1989) 7 IMDS 3.

${ }^{74}$ Rick Butler, 'Front of Mind: Al in Manufacturing' (Insights International, Nov 2018) at p6.

${ }^{75}$ Compare Fritz Bastarz and Patrick Halek, 'Seeing the Wood for the Trees Again! SMART - A Holistic Way of Corporate Governance Offering a Solution Ready to Use' in Constantine Stephanides (ed), Universal Access in Human-Computer Interaction (Heidelberg: Springer 2011) at 187-194 for executive-level decision making in a contextualised and integrated manner.

${ }^{76}$ Deutsche Bank Deploys Al to Help Meet Needs of Regulatory Compliance' (Dow Jones Institutional News, 18 April 2017).

77 'Wolters Kluwer and Chartis Research to Explore Benefits of Al for Managing Regulatory Change' (Businesswire, 2 May 2019); Michelle Quah, 'Smart Data could be Key to Help Restore Trust in Corporate Reporting' (The Business Times, Singapore, 6 March 2019).

${ }^{78}$ Queried in L Thorne-McCarty, 'Finding the Right Balance in Artificial Intelligence and the Law' in Woodrow Barfield and Ugo Pagallo (eds), Research Handbook on the Law of Artificial Intelligence (Cheltenham: Edward Elgar 2018) in ch 3. Also see Frank Pasquale, 'Rule of Persons, Not Machines: The Limits of Legal Automation' (2018), http://ssrn.com/abstract=3135549 arguing that legal interpretation is a human task based on responsible articulation and communication, needing flexibility and understanding of context, and cannot be automated by machines.
} 
enhancing properties of machine learning in corporate compliance work, ${ }^{79}$ which can require the processing of much information as well as tasks. However, machines seem to be serving at the administrative and straightforward ends of the work spectrum, while corporate secretaries' human judgment is still keenly needed in interpreting the needs of legal compliance. ${ }^{80}$

Machine learning is also deployed in evaluative work, where such evaluation is made on the basis of data-driven learning and pattern recognition. For example, companies are using $\mathrm{Al}$ to detect internal control breaches and fraud, as well as to trawl through firm expenses to detect potentially corrupt behaviour. ${ }^{81}$ Kinetic Consulting envisages that $\mathrm{Al}$ would be used in key business processes in the travel, medical, insurance, credit and sales sectors, and would be relevant to Board functions in relation to strategy and risk management. ${ }^{82} \mathrm{Al}^{\prime} \mathrm{s}$ evaluative properties are also useful to the highest echelons in corporations in relation to corporate governance structures and practices. For example, findings made by $\mathrm{Al}$ as to correlations between good governance practices and firm performance based on voluminous data can inform corporate governance practices. ${ }^{83}$ Crucially, these can be used by investors as they monitor for signs of danger or distress at investee firms. ${ }^{84} \mathrm{Al}$ has also been experimented in Board recruitment. A machine is fed voluminous data of the attributes of Board members that have been reappointed to other firms, with reappointment being used as a proxy indicator for desirability of the Board members' attributes. Such a machine can then be consulted upon to determine if candidates before a Board possess similarly desirable attributes. ${ }^{85}$ Further, $\mathrm{Al}$ can be used to evaluate the quality of Board meetings, ${ }^{86}$ to assist with board evaluation, using data relating to quality indicators such as attentiveness to risk management. ${ }^{87}$ In sum, machine learning assists human judgement by overcoming information asymmetry. The use of such machine learning in corporate processes and governance is not arguably paradigm-challenging as the deployment of Al enhances existing corporate governance roles, whether it be shareholder monitoring ${ }^{88}$ or Board

79 'A Robot in the Boardroom- Is The Role of the Company Secretary about to Change?' (Fresh Business Thinking, 2019).

80 'Artificial Intelligence and the Impact on the Company Secretary' (CSSA, Sep 2018).

${ }^{81}$ Michael Volkov, 'Artificial Intelligence, Hype and Misconduct' (Corruption, Crime and Compliance Blog, 25 July 2018).

82 Kinetic Consulting, Al Guide for CEOs and Directors (2017) at www.kineticcs.com/wpcontent/uploads/2017/06/A.I.-Guide-for-CEOs-and-Board-Directors Kinetic-Consulting-Services.pdf.

${ }^{83} \mathrm{Fu}$ Hsiang Chen, Der-Jang Chi, and Chun-Yi Kuo, 'Using Rough Set Theory and Decision Trees to Diagnose Enterprise Distress - Consideration of Corporate Governance Variables' in De-Shuang Huang, Kang-Hyun Jo and Ling Wang (eds), Intelligent Computing Methodologies (Heidelberg: Springer 2014) at 199-209; Darie Moldovan and Simona Mutu, 'Learning the Relationship Between Corporate Governance and Company Performance Using Data Mining' in Petra Perner (ed), Machine Learning and Data Mining in Pattern Recognition (Heidelberg: Springer 2015) at 368-380.

${ }^{84}$ Sining Zhao and Hamido Fujita, 'Predicting the Listing Status of Chinese Listed Companies Using Twin Multiclass Classification Support Vector Machine' in Franz Wotawa, Gerhard Friedrich, Ingo Pill, Roxane KoitzHristov and Moonis Ali (eds), Advances and Trends in Artificial Intelligence. From Theory to Practice (Heidelberg: Springer 2019) at 50-62; Ruibin Geng, Indranil Bose, Xi Chen, 'Prediction of Financial Distress: An Empirical Study of Listed Chinese Companies Using Data Mining' (2015) 241 European Journal of Operational Research 236.

85 Isil Erel, Lea H Stern, Chenhao Tan and Michael S Weisbach, 'Could Machine Learning Help Companies Select Better Boards?' (9 April 2018).

${ }^{86}$ Kieran Moynihan, 'What Will the Board of the Future Look Like?' (2018) Accountancy Ireland on Corporate Governance 72.

${ }^{87}$ Akshaya Kalmanath, 'The Perennial Quest for Board Independence - Artificial Intelligence to the Rescue' (2019) at https://ssrn.com/abstract=3360349.

${ }^{88}$ Theoretically based and justified upon the agency model of corporate governance, see Michael Jensen and William Meckling, "Theory of the Firm: Managerial Behavior, Agency Costs and Ownership Structure" (1976) 3 Journal of Financial Economics 305. Also reflected in the legal regime for shareholder decision rights, such as in 
decision-making. ${ }^{89}$ The division of powers in the respective corporate governance organs remains the same.

However, one queries whether the use of Al changes the relational nature in corporate governance. Where investors use Al to monitor companies' financial and non-financial information and corporate governance practices, they may increasingly converge on certain providers or suppliers of such software. ${ }^{90}$ Would investors using the same Al programs be steered towards homogenous value judgments about their investments? Can such investor behaviour be regarded as coherent with stewardship norms ${ }^{91}$ which require thoughtful engagement by investors? However, it may be argued that this is no different from investors' reliance on proxy advisers today, and investors would owe a similar fiduciary duty to their beneficiaries to consider their vote and engage with them carefully, whether they are assisted by proxy advisers or Al. ${ }^{92}$ However, more fundamentally, the use of Al may pander to humans' behavioural heuristic of deference ${ }^{93}$ as human recipients may readily accept the Al's evaluation in an unquestioning manner. This causes blind reliance without sufficient interrogation into the information completeness and diversity processed by the Al. ${ }^{94}$ This is problematic because machine learning is automated but there is yet no explainability of Al's evaluations. ${ }^{95}$ This raises two issues for corporate governance: first, would Al paradoxically worsen the problem of shareholder passivity in dispersed ownership jurisdictions? Second, how should conflicts of interests be addressed? For example, the supplier from whom the board buys the Al software to augment board-decision making process may also be the provider of Al proxy advisory services to shareholders.

The increased use of machine learning in making higher level, executive and qualitative judgments may not yet pose a challenge to principles or ideology, such as shareholder primacy or directors' duties and accountability in law, but it may have implications for the nature of work replacement or human agency changes in the corporate workplace. ${ }^{96}$ In this manner, incremental legal or regulatory shifts may be called for, and corporate leaders may come under pressure to demonstrate sensitivity

the general meeting, John Armour, Simon Deakin and Suzanne J. Konzelmann, 'Shareholder Primacy and the Trajectory of UK Corporate Governance' (2003) at http://www.cbr.cam.ac.uk/fileadmin/user_upload/centrefor-business-research/downloads/working-papers/wp266.pdf.

${ }^{89}$ Arts 3 and 4, UK Regulations for Model Articles of Private and Public Companies. Theoretical support is found in the economic model for the structure of corporate law, see Armen A Alchian and Harold Demsetz, "Production, Information Costs and Economic Organisation" (1972) 62 The American Economic Rev 777, Frank H Easterbrook and Daniel R Fischel, The Economic Structure of Corporate Law (Cambridge Mass: Harvard University Press 1991).

${ }^{90}$ Martin Carpenter and Ser-Huang Poon, 'Lessons Learned from Al Prototype Designed for Corporate AGM Voting Decisions' (2018) at http://ssrn.com/abstract_id=3244160.

${ }^{91}$ Eg UK Stewardship Code 2020.

92 See SEC, 'Commission Guidance Regarding Proxy Voting Responsibilities of Investment Advisers', Release Nos. IA-5325; IC-33605 (2019) at https://www.sec.gov/rules/interp/2019/ia-5325.pdf.

${ }^{93}$ Alan Dignam, 'Artificial Intelligence: The Very Human Dangers of Dysfunctional Design and Autocratic Corporate Governance' (Queen Mary University of London Working Paper 2019) at https://ssrn.com/abstract=3382342.

94 Ibid.

95 Ibid.

${ }^{96}$ Commentators pay particular attention to the human ability to consider social or other-centred impacts of their decisions, whereas machines are not usually programmed with rules on empathy, if such can indeed be coded, see Paulius Cerka , Jurgita Grigien, Gintare Sirbikyt, 'Liability for Damages Caused by Artificial Intelligence' (2015) 31 Computer Law and Security Review 316. Further, humans often have an intuitive judgment which represents an integrated reasoning/decision based on many aspects. This is highly valuable for qualitative judgment, Mohammad Hossein Jarrahi, 'Artificial Intelligence and the Future of Work: Human-Al Symbiosis in Organizational Decision Making' (2018) 61 Business Horizons 577. 
to changes that affect other constituents. Boards of investor and investee firms may need to demonstrate greater governance oversight of technology use ${ }^{97}$ as well as set strategic agendas for stimulating and governing innovation..$^{98}$ Suppliers of machine learning software may also need to be appropriately governed in terms of the development, accountability and explainability of $\mathrm{Al}$ functions. ${ }^{99}$ Hence, although there may be no radical or fundamental paradigm changes, such as in firms' purposes, corporate governance roles and corporate ideology, there may be a need for norms to be considered in relation to technology and the corporate workplace. More on such legal reform is discussed in Section C.

\section{Incremental/Facilitative DLT}

DLT may be attractive for businesses where coordination costs need to be lowered amongst various actors, such as in supply chain management, ${ }^{100}$ trade finance, ${ }^{101}$ settlement and clearing of financial transactions, ${ }^{102}$ situations where multiple parties are involved and where there are needs for verification and checking at a number of intermediate levels. These efficiencies, driven by the operation of computational logic on a single ledger and the transparency of the ledger to all participants, can augur greater changes at executive levels of working and at the corporate governance level.

Murray et al ${ }^{103}$ explore how DLT's coordinative properties can be applied to the agency-based paradigm in corporate governance. DLT's flattened structure for participation offers the possibility to reconsider the hierarchical structures in corporate governance, such as Board monitoring of senior

\footnotetext{
${ }^{97}$ Eve Tahmincioglu, 'The Board's Role in Setting Up Al's Ethical 'Guardrails" (2019) The Character of the Corporation: Ethics and Technology 32; Andrea Bonine-Blanc, 'Technology, Trust and Ethics: An Actionable Governance Toolkit for a Disruptive Time' (Carrier Management, Sep 2018).

${ }^{98}$ Colin Coulson-Thomas, 'Board Leadership of Innovation in Contemporary Circumstances' (2019) at 29th World Congress on Leadership for Business Excellence and Innovation, India's Institute of Directors, https:// www.iodglobal.com/dubai-global-convention-2019.html; Roger M Barker and Iris H-Y Chiu, 'From Value Protection to Value Creation- Rethinking Corporate Governance for Promoting Firm Innovation' (2018) Fordham Journal of Corporate and Financial Law 437.

${ }^{99}$ The governance of Al is championed in Dignam (2019) and John Frank Weaver, 'Regulation of artificial intelligence in the United States' in Woodrow Barfield and Ugo Pagallo (eds), Research Handbook on the Law of Artificial Intelligence (Cheltenham: Edward Elgar 2018) in ch7.

${ }^{100}$ Adam Sulkowski, "Blockchain, Business Supply Chains, Sustainability, and Law: The Future of Governance, Legal Frameworks, and Lawyers" (2019) 43:2 Del J Corp L 303 such as in relation to ESG certifications, Jan Mendling et al, 'Blockchains for Business Process Management - Challenges and Opportunities' (2018) 9 ACM Transactions on Management Information Systems 4; Xiongfeng Pan, Xianyou Pan, Malin Song, Bowei Ai, Yang Ming, 'Blockchain Technology and Enterprise Operational Capabilities: An Empirical Test' (2019) International Journal of Information Management at https://doi.org/10.1016/j.ijinfomgt.2019.05.002.

${ }^{101}$ Vedat Akgiray, 'The Potential for Blockchain Technology in Corporate Governance' (OECD Working Paper 2019) at https://dx.doi.org/10.1787/ef4eba4c-en.

102 Joseph Lee, 'Distributed Ledger Technologies (Blockchain) in Capital Markets: Risk and Governance' (2018) at https://papers.ssrn.com/sol3/papers.cfm?abstract id=3180553; Emilios Avgouleas and Aggelos Kiaiyas, 'The Promise of Blockchain Technology for Global Securities and Derivatives Markets: The New Financial Ecosystem and the 'Holy Grail' of Systemic Risk Containment' (2019) 20 European Business Organisations Law Review 81. ${ }^{103}$ Alex Murray, Scott Kuban, Matthew Josefy and Jon Anderson, 'Contracting in the Smart Era: The Implications of Blockchain and Decentralized Autonomous Organizations for Contracting and Corporate Governance' (2019) Academy of Management Perspectives (forthcoming).
} 
executives ${ }^{104}$ and shareholder monitoring of Boards. ${ }^{105}$ Further, such flatter structures for participation open up possibilities for rethinking if corporate governance should be confined to its traditional organs of the Board and shareholders. ${ }^{106}$ The contemporaneous transparency of the DLT potentially allows corporate information to be shared for monitoring purposes. ${ }^{107}$

At an incremental level, DLT seems to be heartily adopted as a new means for conducting shareholders' general meetings to overcome the limitations of traditional physical meetings (which have nevertheless improved over the years with the legal acceptance of electronic notices and proxy voting). ${ }^{108}$ The Australian and Indian Stock Exchanges are promoting e-meetings conducted using DLT ${ }^{109}$ while the Delaware General Corporation Law has been amended to allow corporations to use DLT to maintain stock ledgers and communicate with shareholders. ${ }^{110}$ Companies may voluntarily take up DLT to facilitate general meetings as the perception of ease of access and facilitation of voting can be seen to be shareholder-friendly in nature. ${ }^{111}$ However, Nord ${ }^{112}$ warns that managers can also use DLT meetings to 'divide and conquer' shareholders, as shareholders may not perceive the need for or have less time to work together to put pressure on Boards. This may reduce shareholder engagement in the sense of reduced informal engagement with Boards. Further, DLTenabled voting can potentially speed up voting processes and reinforce shareholders' tendency towards least resistance by voting with management. This may paradoxically result in less monitoring by shareholders in dispersed ownership jurisdictions and an entrenchment of controller's powers in concentrated ownership jurisdictions. This will be examined in Section C.

In one sense, the use of DLT for general meetings may be regarded as incremental as the forum of meetings is changed, but fundamental legal principles relating to information disclosure, how resolutions are put on the agenda, how voting is carried out and counted and how decisions are made, remain. The use of DLT does not per se change the paradigm for the legal principles of the general meeting and for shareholders' rights.

\footnotetext{
${ }^{104}$ Commentators have different visions as to how this pans out. Petrin (2019) takes the view that there is no longer a need for this hierarchical layer and that fused Boards that include management capability will develop as Board functions become automated by Al. Enriques and Zetzsche (2019) take a different view that the monitoring Board makes value judgments and cannot be automated or fused with management.

105 Radical visions include shareholder real-time monitoring, Murray et al (2019) above, although Enriques and Zetzsche (2019) doubt that shareholders are incentivised to do so. Boards may become redundant as decisionmaking can revert to the general meeting, Murray et al (2019) above, and more to be discussed.

106 Perhaps to allow stakeholder participation, see Pam Ly, 'Blockchain Technology: Its Ability to Transform Corporations' CSR Practices' (2018) 22 International Trade and Business Law Review at http://ssrn.com/abstract id=3384352. A more fundamental change such as platform governance will be discussed below.

107 Such as real-time accounting, see Murray et al (2019); Akgiray (2019); David Yermack, 'Corporate Governance and Blockchains' (2017) 21 Review of Finance 1.

108 UK Companies Act 2006 s303, European Shareholder Rights Directive 2007.

109 'NSE to Test E-voting Using Blockchain' (Express Computer, 27 Sep 2018) ie India's exchange to pilot listed cos using blockchain to conduct shareholder voting; Christoph van der Elst and Anne LaFarre, 'Blockchain and Smart Contracting for the Shareholder Community' (2019) 20 European Business Organisations and Law Review 111.

${ }^{110}$ Travis J Laster, Marcel T Rosner, 'Distributed Stock Ledgers and Delaware Law' (2018) 73 Business Lawyer 319.

111 'Santander uses blockchain for investors' vote' (Financial Times 21 May 2018).

112 Spencer J Nord, 'Blockchain Plumbing: A Potential Solution for Shareholder Voting?' (2019) 21 University of Pennsylvania Journal of Business Law 706.
} 
Van der Elst and LaFarre, writing in the European context, ${ }^{113}$ and Geis, writing in the US context, ${ }^{114}$ crucially argue that the identity of the shareholder can be a contested notion. Individuals who purchase shares in a company frequently have these shares registered in the name of the custodian of the electronic scrips of ownership, usually a bank, entitling the custodian to legal rights of share ownership such as participating in general meetings and voting. There is usually no coordination attempted on the part of custodians to enable beneficial owners to exercise corporate governance rights, nor do custodians necessarily vote their shares or engage in corporate governance. Where individuals purchase units in a fund that invests in corporate equities, such funds are legal owners of company shares and corporate governance rights. ${ }^{115}$ They can take into account beneficiaries' wishes in relation to investee companies, ${ }^{116}$ but this is not explicitly required nor are beneficiaries necessarily knowledgeable or incentivised enough to provide such instructions. Beneficiaries' legal entitlements regarding corporate governance are highly questionable because of the interposition of fund structures for investment, which cannot be said to confer equitable ownership of particular shares on beneficiaries who are part of a common pool of investees. ${ }^{117}$

Further, funds that own shares and are entitled to corporate governance rights may delegate to asset managers their proxy voting rights. The implications of the investment chain for corporate governance as observed are voting apathy and a general lack of engagement by asset managers and funds in their investee companies. ${ }^{118}$ In this light, policy makers have urged institutional shareholders to assume the mantle of stewardship ${ }^{119}$ so as to plug a monitoring vacuum seen as contributory to corporate scandals and disasters. ${ }^{120}$ There is potential for DLT to change the state of institutional shareholder stranglehold on corporate governance if the use of DLT is able to penetrate the layers of the investment chain to identify share ownership and allocate shareholder rights to beneficiaries.

Where the individual beneficial owner is obscured by the financial institution custodian that holds the legal right to shares, DLT can be used to record levels of intermediated securities ownership, ultimately identifying and empowering beneficial share owners to exercise corporate governance rights. ${ }^{121}$ It is less clear that DLT can be used to identify and allocate shareholder rights to

\footnotetext{
113 "Christoph van der Elst and Anne LaFarre, 'Blockchain and Smart Contracting for the Shareholder Community' (2019) 20 European Business Organisations and Law Review 111.

${ }^{114}$ George S Geis, 'Traceable Shares and Corporate Law' (2018) 113 Northwestern University Law Review 227.

115 These issues are discussed in BIS, Exploring the Intermediated Securities Holding Model (2016) at https://www.uksa.org.uk/sites/default/files/BIS RP261.pdf; and UK Law Commission, Intermediated Securities- Call for Evidence (Aug 2019) at https://s3-eu-west-2.amazonaws.com/lawcom-prod-storage11jsxou24uy7q/uploads/2019/08/6.5925 LC Intermediated-securities-call-for-evidence-web.pdf.

${ }^{116}$ Ewan McGaughey, 'Does Corporate Governance Exclude the Ultimate Investor?' (2016) 16(1) Journal of Corporate Law Studies 221.

117 John Morley, 'The Separation of Funds and Managers: A Theory of Investment Fund Structure and Regulation' (2014) 123 Yale Law Journal 1231.

118 Paul Myners, Institutional Investment in the UK: A Review (2001); later see David Walker, A Review of Corporate Governance in Banks and Financial Institutions (Nov 2009). The apathy of shareholders was especially critiqued in the wake of the 2007-9 global financial crisis, see "FSA Chief Lambasts Uncritical Investors", Financial Times (11 March 2009) and "Myners Lashes out at Landlord Institutional shareholders", Financial Times (21 Apr 2009).

${ }^{119}$ Iris H-Y Chiu, 'Institutional shareholders as Stewards: Towards a New Conception of Corporate Governance?' (2012) 6 Brooklyn Journal of Financial, Corporate and Commercial Law 387; 'Turning Institutional Investors into "Stewards"- Exploring the Meaning and Objectives in "Stewardship"' (2013) Current Legal Problems 1.

${ }^{120}$ Walker (2009).

${ }^{121}$ Van der Elst and LaFarre (2017); Yermack (2017); Akgiray (2019).
} 
beneficiaries in funds that invest in corporate equities as these beneficiaries' property can only be traced to units in funds and not to particular shares. Nevertheless, commentators take the view that a new cadre of beneficial owners can be brought into the corporate governance landscape and corporate governance can become relevant to those outside the institutional sector. ${ }^{122}$ However, the magnitude of change is questionable. Savers in Europe and the UK save in banks or through funds instead of investing directly in the stock market. ${ }^{123}$ Further, it is uncertain if the new cadre of shareholders would be incentivised to exercise their rights. ${ }^{124}$ Indeed, even if beneficiaries can be identified and even if they do vote, it is far from clear that they will vote in a manner that effectively acts as a check on management. Actually, it is entirely possible that they will vote with management. It is doubtful that these beneficial shareholders will voluntarily incur time, effort and money to conduct their own due diligence so as to vote in an informed manner, in view of the free rider problem and coordination cost. Further, although DLT can theoretically host corporate information for beneficial shareholders to view, such information is likely to be raw data, not organised in terms of complex cost benefit analyses that a reasonable investor would want to know in connection with the proposed resolutions.

Changes in the transparency of share ownership would also entail rethinking in terms of shareholding transparency and disclosure as currently regulated in securities markets. The US rule requiring intentions-based disclosure at $5 \%$ of share ownership and the UK rule that compels disclosure of stakebuilding from $3 \%$ onwards is designed to strike a balance between market freedom and transparency for markets to anticipate behaviour. The DLT's capacity for real-time transparency brings about a choice for policy. If transparency benefits efficient markets, ${ }^{125}$ there is little reason not to support real-time transparency. However, commentators are of the view that this would impact shareholder conduct that is designed to be strategically opaque within the parameters of current disclosure requirements, such as hedge fund activist strategies of building stakes secretly until disclosure thresholds are triggered. ${ }^{126}$ Deterring or undermining hedge fund activism is not necessarily a good thing if one takes the view that hedge fund activism has the capacity to monitor and discipline managers in a dispersed ownership jurisdiction and control shareholders in a concentrated ownership jurisdiction. As technology is not deterministic of policy choice, real-time transparency is still a policy choice that has to be made. ${ }^{127}$

\section{Radical/Disruptive Al}

At a radical/disruptive level, the key characteristic is arguably replacement or displacement of human agency in roles traditionally thought to be incapable of assumption by robots- not the sales assistant but the lawyer or the judge, ${ }^{128}$ not the administrative secretary but the directors on the

\footnotetext{
122 Van der Elst and LaFarre (2017); Magnier at al (2018).

123 'Germans reluctantly switch to stock market in search of returns' (Financial Times, 19 April 2019); UK individuals make up about $12 \%$ of the ownership of quoted company shares, according to the Office of National Statistics in 2016, at https://www.ons.gov.uk/economy/investmentspensionsandtrusts/bulletins/ownershipofukquotedshares/201 $\underline{6}$.

${ }^{124}$ Enriques and Zetzsche (2019) doubt this.

125 The efficient capital markets hypothesis, see Eugene Fama, 'Efficient Capital Markets: A Review of Theory and Empirical Work' (1970) 25 Journal of Finance 383.

126 Yermack (2017), Akgiray (2019).

127 Sections B and C.

${ }^{128}$ Suggested in Richard and Daniel Susskind, The Future of the Professions (Oxford: OUP 2017).
} 
corporate Board. ${ }^{129}$ At this level, we are looking at equivalence in the perception of capability between humans and robots in relation to tasks that require composite skills, such as the 'mediating', ${ }^{130}$ 'monitoring', ${ }^{131}$ and judgment-based tasks ${ }^{132}$ of directors, and even competition between humans and robots in the same spheres of discretionary or qualitative judgments and skills.

Many legal issues arise at the radical/disruptive level, and will not be functionally determined. This is because radical/disruptive applications of $\mathrm{Al}$ affect core corporate law and governance norms and compel policy choices to be made. The key issues are enumerated as follows:

(a) where does responsibility or liability attach for harm?

In March 2018, Uber's self-driving taxi struck a pedestrian in Tempe, Arizona while the back-up driver was watching The Voice on video streaming app Hulu. ${ }^{133}$ The Yavapai County Attorney determined that Uber Corporation would not be charged with a crime although it remains unclear if the back-up driver would be personally charged.

However, two questions should be raised. One is whether it is clearly the negligence of the back-up driver i.e. personal liability, and the second is whether Al failure should entail responsibility or liability on the part of the software provider, i.e. a form of product liability. On the first, if the backup driver is regarded as a 'driver', then failure to stop in time before hitting a pedestrian amounts to negligence, even if the pedestrian was contributorily negligent. However, if we regard the back-up driver's job as not to drive but to monitor instead, i.e. to monitor the Al for errors, then it has to be asked what reasonable standard of care entails in monitoring and not in driving. ${ }^{134}$ Such a standard of care could in part depend on human expectations of Al performance, which could be unpredictable as machine learning is inherently unpredictable. ${ }^{135}$ In the alternative, if one makes an analogy with airplane piloting which always requires two pilots to be on board even if autopilot technology is deployed for much of all flights, ${ }^{136}$ is Uber negligent for removing the second back-up driver? ${ }^{137}$ Should the same standard of care for corporate systems and procedures be applied to airplane piloting as to driverless cars? Where a corporation has been grossly negligent in not taking reasonable steps in its systems and procedures to prevent a breach of duty of care, it can be criminally liable under the UK Corporate Homicide and Manslaughter Act. ${ }^{138}$ The inquiry above

\footnotetext{
${ }^{129}$ Petrin (2019); Florian Möslein, 'Robots in the Boardroom: Artificial Intelligence and Corporate Law' in Woodrow Barfield and Ugo Pagallo (eds), Research Handbook on the Law of Artificial Intelligence (Cheltenham: Edward Elgar 2018) in ch25.

${ }^{130}$ Enriques and Zetzsche (2019).

131 Ibid.

132 Petrin (2019).

133 'Uber won't be charged with fatal self-driving' (5 March 2019, the verge.com).

${ }^{134}$ See Curtis EA Karnow, 'The Application of Traditional Tort Theory to Embodied Machine Intelligence' in Ryan Calo, A. Michael Froomkin and lan Kerr (eds), Robot Law (Cheltenham: Edward Elgar 2016) at ch3 where it is argued that the standard of care must evolve according to what reasonable standards of behaviour are expected where human agents work alongside or monitor robots and learn the patterns of robots' behaviour. 135 Lodder (2019).

136 'How Airline Crews Work' in https://science.howstuffworks.com/transport/flight/modern/airlinecrew1.htm.

${ }^{137}$ Although it was reported that Uber had lined up two back-up drivers and made a policy decision to remove one before the occurrence of the March 2018 fatality, see n133.

${ }^{138}$ Ss1-2 of the legislation, see R. v Cotswold Geotechnical Holdings Ltd [2011] EWCA Crim 1337; R. v Cornish (Errol) [2016] EWHC 779 (QB) which exposes the difficulties in making a corporation responsible if the chain of command is long and systems of governance are in place.
} 
reflects the need for new interpretations of the negligence thresholds in relation to new forms of human agency alongside the robot that performs certain primary tasks.

On the second question, product liability for software has been a tricky legal question for a long time, as it is not yet clear if software is a 'product' subject to strict product liability rules ${ }^{139}$ regarding defects, ${ }^{140}$ or whether software is provided as a service. Where the latter applies, the legal responsibility for software bugs is based on the tort of negligence which requires finding that the software provider has fallen below the reasonable man's standard of care. ${ }^{141}$ This standard is difficult to prove as software bugs are inherently impossible to fix completely before release. ${ }^{142}$ One can appreciate that an application of a strict or stricter liability standard would likely provide the necessary incentive to make software development more conservative, ${ }^{143}$ but how this may affect the incentive to innovate should be investigated. ${ }^{144}$

That said, the issue of strict or stricter product liability assumes that the Al software producer should be liable. This may not be the case. Consider again the self-driving car example. When an accident occurs, should responsibility lie with the car-maker, the designer of the self-driving system, the developer of the sensing software or perhaps the passenger himself? ${ }^{145}$ Further, product liability for Al software assumes that the end users or consumers do not play any role in the functioning of the software. But where proper functioning requires input from consumers, in the sense that they have to feed appropriate data into the Al machine, it is not clear if the consumer should be exempted from responsibility. Putting it differently, product liability for Al assumes that the defect in the product is caused by the original programming of the Al. But Al deploys neural networks and can function and arrive at decisions outside the scope of its original programming, due in part to subsequent human intervention (involving consumers or end users). It is not clear that liability should be restricted only to the producers of Al software. In the scenario where radical/disruptive Al is adopted, such as Al being appointed to have equivalent status as a human Board director or being the Board as such, the two issues discussed above similarly arise. Where a poor directorial decision is made that results in corporate loss, will personal or product liability attach? Petrin posits that only

${ }^{139}$ EU product liability rules are stricter (Duncan Fairgrieve and Richard S Goldberg (eds), Product Liability ( $3^{\text {rd }}$ ed, Oxford: Oxford University Press 2019) at Part II, chs 7-13) compared to the negligence and balancing standards upheld in the US. But in the latter case, the complexity of robot design and the interrelation of parts and software may make it difficult to apply traditional doctrines of defects and standards of care, $F$ Patrick Hubbard, 'Allocating the Risk of Physical Injury from "Sophisticated Robots": Efficiency, Fairness, and Innovation' in Ryan Calo, A. Michael Froomkin and lan Kerr (eds), Robot Law (Cheltenham: Edward Elgar 2016) at ch2.

${ }^{140}$ Computer Associates UK Ltd v The Software Incubator Ltd [2018] EWCA Civ 5181 determined that 'goods' are tangible and moveable property and software does not constitute goods, but the Supreme Court is referring the case to the Court of Justice of the EU to determine if the strict liability laws under European Directive for product liability should cover software.

${ }^{141}$ Karen Goetzel, 'Legal Liability for Bad Software' (2016) 29 Crosstalk 23.

142 Bryan H Choi, 'Crashworthy Code' (2019) 94 Washington Law Review 39.

${ }^{143}$ David C Vladeck, 'Machines Without Principals: Liability Rules and Artificial Intelligence' (2014) 89

Washington Law Review 117 proposing a standard of strict liability for software providers.

${ }^{144}$ Choi (2019); Brandon W Jackson, 'Artificial Intelligence and the Fog of Innovation: A Deep-Dive on Governance and the Liability of Autonomous Systems' (2019) 35 Santa Clara Technology Law Journal 35 argue that strict liability rules put a brake on innovation but to shield corporations from this may also over-subsidise their activities, leading to an incentive to oversupply hazardous activities, Gerhard Wagner, 'Robot Liability' (2018) at http://ssrn.com/abstract=3198764.

${ }^{145}$ Andrew Austin, "Product Liability in the Al Age" Freshfield Bruckaus Deringer https://www.freshfields.com/en-gb/our-thinking/campaigns/digital/artificial-intelligence/product-liability-inthe-ai-age/. 
product liability is relevant as there is no further relevance for personal liability. ${ }^{146}$ If shareholders appoint Al to be the management organ, shareholders would not sue themselves for being negligent principals. Möslein ${ }^{147}$ also posits that where the ex post accountability of an Al director is irrelevant, as there is no capacity to account nor compensate, Al directors have to be ex ante programmed to discharge directors' duties. But he queries how such duties can be 'internalised' by machine learning. Can we really fuse the requirements of corporate law into product liability law? In this respect, a number of commentators have opined that a regulatory agency ${ }^{148}$ setting ex ante governance standards may be optimal, and this would also apply to software standards ${ }^{149}$ and entail the liability of software providers. However, the implications of such a conclusion are stark and disturbing- is entrepreneurial leadership capable of being codified and standardised? Are regulatory agencies for corporate governance standards well-placed to govern Al development for the purposes of conducting the economy, wealth creation and distribution? These challenges in adopting policy choices would likely affect the extent to which Al is allowed to effect radical/disruptive changes in corporate law and governance.

Next, should Al be regarded as a legal person by virtue of its capabilities in performing autonomous acts and what would be the implications?

(b) Should the Al be treated as a legal person?

It has been opined that as we have created artificial legal persons in the form of corporations, there is no stopping the law from recognising $\mathrm{Al}$ as legal persons executing autonomously determined tasks. ${ }^{150}$ However, corporate personalities, whether dating back to Roman cities or to the modern corporation, are essentially human as they showcase collective human agency, making the need to have a legal personality necessary in order to distinguish themselves from individual human agency, as well as to secure a communitarian commitment. ${ }^{151}$ Further, the relevance of legal personhood is not merely conceptual, but instrumental in nature- what purposes are served by conferring legal personhood? The instrumental perspective ${ }^{152}$ is not wrong as the modern corporations' legal personality has always been seen as a policy choice to facilitate progress and development since the Industrial revolution. ${ }^{153}$

If Al has legal personality, an important question is whether it can be held liable for harms caused by it. But such liability may have little real consequence if the Al can neither compensate victims of

\footnotetext{
146 Petrin (2019).

147 Möslein (2018).

148 Jackson (2019) above on the roles of legislators, regulators and courts, and Weaver (2018) above.

${ }^{149}$ Roksanda Moore, 'Standardisation: A Tool for Addressing Market Failure Within the Software Industry' (2013) 29 Computer and Security Law Review 213.

${ }^{150}$ Shawn Bayern, 'The Implications of Modern Business Entity Law for the Regulation of Autonomous Systems' (2015) 19 Stanford Technological Law Review 93.

${ }^{151}$ Sergio Gramitto, 'The Technology and Archaelogy of Corporate Law' (2019) at http://ssrn.com/abstract=3232816.

152 There are other perspectives such as those that delve into the meaning of personhood, and defend the freedom of will where there is sentience, F Patrick Hubbard, 'Do Androids Dream? Personhood and Intelligent Artifacts' (2010) at http://ssrn.com/abstract=1725983; Evan J Zimmermann, 'Machine Minds: Frontiers in Legal Personhood' (2017) at http://ssrn.com/abstract=2563965 who argues that legal personhood can save a programme from being terminated.

153 The concession theory of the corporation posits that corporations attain legal personality but comply with transparency conditions set by the state in order to further economic development and progress.
} 
harm ${ }^{154}$ nor be made to suffer and realise the import of punishment. Imposing liability on Al may have the consequence of insulating corporations or other principals that deploy $\mathrm{Al}$ as well as Al software providers from liability. This may promote irresponsible economic conduct or corporate behaviour.

On the other hand, it can be argued that corporations should not be crippled by punishing penalties for experimenting with innovation ${ }^{155}$ and the legal personhood of the Al that interrupts the attribution of liability to corporations that develop or deploy them could be a sound policy choice to limit the cost of innovation. This could pave the way for other forms of cost-sharing the risks and harms to society, such as having compulsory insurance or a minimum paid-up capital policy for Al with legal personalities. ${ }^{156}$

Nevertheless, there may be no incentive on the part of corporations or shareholders to support Al gaining legal personhood even with the benefit of being shielded from liability. This is because legal personhood carries certain implications such as rights. If Al has rights over property or profits, ${ }^{157}$ this would create uncertainty for corporations and their shareholders in relation to how wealth should be distributed and appropriated. The question regarding rights for $\mathrm{Al}$ are further enumerated below.

(c) Rights for the Al?

Schirmer raises scepticism regarding the wisdom of conferring upon Al rights such as those conferred upon natural persons and prefers to base the legal capacity of Al on the functions it serves. ${ }^{158}$ What 'rights' are appropriate and conferrable on Al as legal persons opens up a Pandora's box. Also, who would determine these policy choices?

Corporate groups can use the legal personhood of Als to conduct controversial learning, such as in weapons, drugs or other controversial products, just like how subsidiaries are traditionally used for the purpose of partitioning assets in risky businesses and jurisdictions. ${ }^{159}$ Indeed, LoPucki goes as far as to say that algorithmic entities would most certainly be deployed to conduct illegal or severely high risk activities. ${ }^{160}$ In this regard, should Al subsidiaries be treated differently under English law from other subsidiaries, i.e. the latter of which enjoy separate legal personality and are not implicated in enterprise liability? ${ }^{161}$ Or should a different policy choice be made?

\footnotetext{
${ }^{154}$ Robert van den Hoven van Genderen, 'Legal Personhood in the Age of Artificially Intelligent Robots' in Woodrow Barfield and Ugo Pagallo (eds), Research Handbook on the Law of Artificial Intelligence (Cheltenham: Edward Elgar 2018) in ch8.

${ }^{155}$ Choi (2019).

156 Wagner (2018).

${ }^{157}$ Gramitto (2019) on Roman law on slavery as an analogy for the corporate law paradigms involving Al at Board level.

${ }^{158}$ Schirmer (2019).

${ }^{159}$ See Henry Hansmann and Reinier Kraakman, 'Organizational Law as Asset Partitioning' (2000) 44 European Economic Review 807; Larry Cata Backer, 'The Autonomous Global Enterprise: On the Role of Organizational Law Beyond Asset Partitioning and Legal Personality' (2006) 41 Tulsa Law Journal at http://papers.ssrn.com/sol3/papers.cfm?abstract_id=880730.

160 Lynn M Lopucki, ‘Algorithmic Entities' (2018) 95 Washington University Law Review 887.

161 There is no doctrine of enterprise liability in the UK, Adams v Cape Industries plc [1990] Ch 433; Prest v Petrodel Resources Ltd [2013] UKSC 34, [2013] 2 AC 415. Case law has made a small inroad with regard to a parent company's direct duty of care where circumstances of control exist, but this area is still in development, see Chandler v Cape plc [2012] EWCA Civ 525; Ogale Community v Royal Dutch Shell [2018] EWCA Civ 191, Vedanta $v$ Lungowe \& Ors [2019] UKSC 20.
} 
It is also queried whether Al should have rights under employment or labour law, countervailing the arguments raised in the grievances of displaced human agency from jobs. Should Al have citizenship rights such as political rights? This would introduce questions relating to the conceptual nature of citizenship and the practical risks of corporate manipulation of democratic systems. ${ }^{162}$

Ultimately, is an agency such as the Companies Registration House able to accommodate new functions in determining if Al should be given legal personalities and what rights entail? Should such rights be granted in a limited but standardised set or should each right be considered and vetted before being granted on a case by case basis? It would also be challenging to consider the full matrices of pros and cons of rights under either approach as unintended consequences are bound to occur.

The issue of considering rights raises a plethora of issues including incentives, social trust, shifts in power, accountability, regulability and governance. The complexification of the space for law, institutions and governance with the radical/disruptive advent of Al shows a similar trajectory where radical/disruptive DLT is concerned.

\section{Radical/Disruptive DLT}

As discussed above, DLT when deployed in the context of identifying and empowering shareholders has the potential to create radical change. This is because actors that are placed in lesser or disempowered positions within existing institutions can be unshackled and allocated a position of newly exercisable power in the distributed and peer-to-peer structure of the DLT. DLT can facilitate changes that directly challenge existing institutions based on presumed allocations of authority or power. We discuss three key issues below namely the flattening of power structures that DLT can facilitate, the need to consider new governance norms, and the new configurations of legal rights brought about by tokenisation in the DLT economy.

(a) Shifts in structure of economic agency and implications for the corporate economy

The peer-to-peer nature of DLT is not novel, as the platform economy has already ushered in a peerto-peer model for business that challenges the corporate economy. The platform economy is based on the idea of marketizing access to assets instead of promoting traditional consumption to attain ownership of whole assets. ${ }^{163}$ This idea is possible as certain large assets like a home or car may be underutilised at times. ${ }^{164}$ Marketizing access to such assets, such as in the home-sharing or ridesharing business models of AirBnB, Couchsurfing, Uber, Lyft, and BlaBlaCar etc., can meet a variety of urban consumption needs. ${ }^{165}$ There is no longer a necessary hierarchical divide between business and retail, as platforms allow retail-level participants to assume economic agency like businesses, but perhaps on a more casual basis. This can be quite empowering, as some people can supplement

\footnotetext{
162 Van den Hoven van Genderen (2018); Woodrow Barfield, 'Towards a Law of Artificial Intelligence' in Woodrow Barfield and Ugo Pagallo (eds), Research Handbook on the Law of Artificial Intelligence (Cheltenham: Edward Elgar 2018) in ch1.

${ }^{163}$ Arun Sundarajan, The Sharing Economy (Mass: MIT Press 2016) at ch1; Rachel Botsman and Roo Rogers, What's Mine is Yours: How Collaborative Consumption is Changing the Way We Live (Collins, 2011).

164 Sundarajan (2016).

165 Michele Finck; Sofia Ranchordas, 'Sharing and the City' (2016) 49 Vand. J. Transnat'I L. 1299.
} 
their main income ${ }^{166}$ with income from holiday lets on AirBnB or occasional jobs on TaskRabbit. ${ }^{167}$ The DLT-based economy extends opportunities for new economic agency further by offering new forms of commoditisation and peer trading such as peer-to-peer energy trading. ${ }^{168}$

As economic agency on DLT systems are effected by smart contracts, economic agency is highly predefined and precise. However, contracts may be incomplete, especially if off-chain activity is required. For the purchase and sale of crypto-kitties, smart contracts may effect purchase and sale, transfer of value and ownership and recording of transactions. Such a system is entirely on-chain as it relates to crypto-goods or services. However, where DLT is used to effect transactions that still require off-chain delivery, such as goods or services located elsewhere in cyberspace or physically, then there is room for error, default and dispute to arise. Given the irreversibility of the DLT's transaction record, how would off-chain deviations be dealt with and what implications would this have for the ledger? ${ }^{169}$ Would the laws that apply to the sale of goods or contracts still be applicable in light of the peer-to-peer nature of the transaction and the operation of smart contracting on an ex ante basis? ${ }^{170}$

The peer-to-peer nature of the DLT economy and its system of ex ante smart contracting raise new questions regarding the nature of new economic agency and whether rights need to be redefined. Policy choices have only been slowly developing for the platform economy to bring them in line with social expectations of their novel economic agency. ${ }^{171}$ We turn to new needs for governance in the DLT economy.

(b) New governance needs, structures and norms in DLT systems

It has been written at length that the disintermediated, peer-to-peer nature of the DLT system means that no institutions of governance can be ascertained with confidence. ${ }^{172}$ Indeed, not having conventional institutions may be its design and hallmark in the ethos of rejecting the tyrannies and

\footnotetext{
${ }^{166}$ Diana Farrell, Fiona Greig, and Amar Hamoudi, 'The Evolution of the Online Platform Economy: Evidence from Five Years of Banking Data' 109 AEA Papers and Proceedings 362-366 (2019); Deborah Meilhan, 'Customer Value Co-Creation Behavior in the Online Platform Economy' (2019) 7 Journal of Self-Governance and Management Economics 19.

${ }^{167}$ Willem Pieter De Groen, Zachary Kilhoffer, Karolien Lenaerts and Nicolas Salez, 'The Impact of the Platform Economy on Job Creation' (2017) 6 Intereconomics 345 show that just over $10 \%$ of workers in the EU are carrying out full-time economic activity on platforms.

${ }^{168} \mathrm{https}$ ://wepower.network/. Peer-to-peer energy trading is growing in a number of Continental countries, Thomas Morstyn et al, 'Using Peer-To-Peer Energy-Trading Platforms to Incentivize Prosumers to Form Federated Power Plants' (2018) 3 Nature Energy; Jodie Giles, "Peer to Peer Trading and Microgrids - the next Big Thing?". Regen, 21 February 2018, https://www.regen.co.uk/peer-to-peer-trading-and-microgrids-thenext-big-thing/.

169 Usha R Rodrigues, 'Law and the Blockchain' (2019) 104 lowa Law Review 680; Michèle Finck, Blockchain Governance and Regulation in Europe (Cambridge: CUP 2018); Daniel Kraus, Thierry Obrist and Olivier Hari (eds), Blockchains, Smart Contracts, Decentralised Autonomous Organisations and the Law (Cheltenham: Edward Elgar 2019).

${ }^{170}$ Sarah Green, 'Smart Contracts: Interpretation and Rectification' (2018) LMCLQ 234.

${ }^{171}$ Sofia Ranchordás, 'Digital Agoras: Democratic Legitimacy, Online Participation and the Case of Uberpetitions' (2017) 5 Theory and Practice of Legislation 31; Ferreri and Sanyal (2018); Ebru Tekin Bilbil, 'New Governance and Digital Platform Companies: The Case of Uber' (2017) International Journal of Public Administration in the Digital Age (forthcoming), https://ssrn.com/abstract=3028543.

172 Flood and Lachlan (2016).
} 
power structures of conventional institutionalised systems. ${ }^{173}$ At scale, the DLT economy gives rise to questions of whether conventional governance norms such as corporate governance should apply, and whether new needs of governance should be met by new norms.

Commentators are of the view that there is a need for governance in DLT systems, ${ }^{174}$ despite the progress made by DLT in solving the Byzantine Generals' Coordination Puzzle. As Low and Teo argue, the coordination problem solved by the bitcoin blockchain relates only to preventing double spending and maintaining the veracity of the single record in the ledger. ${ }^{175}$ This is premised upon dispersal of power amongst nodes and the operation of incentives consistent with micro-economic assumptions. Where these assumptions do not hold, even the core coordination problem can be compromised. Further, other governance issues are not addressed, such as whether there is a need for authority institutions to respond to urgent needs or resolve problems among participants. The lack of clear institutions of authority on the DLT allows for defaultisation to majority control. This has resulted in rogue behaviour to prevail on a number of cryptocurrency blockchains since a rogue majority that attains $51 \%$ control of the nodes can effect miscreant behaviour such as hacking and theft. ${ }^{176}$ In each case, the founder developers of the DLT system would intervene and create a fork in the blockchain so that rogue behaviour is not legitimised in the forked chain. ${ }^{177}$ However, this creates governance by forking i.e. moving clusters of users away into a different 'community' existing alongside the previous community, without any further governance over rogue behaviour. Such governance is minimal and primitive as it avoids norm development, prevention and sanctioning, and the DLT eco-system is retarded in developing social character and culture. It may nevertheless be argued that the development of sociology in DLT eco-systems must be kept to a minimum so as not to create rules of inclusion/exclusion, which are against the ethos of an open DLT system.

Where the conduct of economic activity or agency is concerned, it is queried to what extent economic activity or agency can flourish without the support of institutions, such as legal institutions, for commercial certainty and to incentivise investment? The need to resolve ex post problems is the raison d'être for the rise of institutions for dispute resolution, law and justice. ${ }^{178}$ To date, the most successful peer-to-peer marketplaces or platform economies, such as eBay, Amazon, Alibaba and AirBnB, and new financial sector actors, such as peer-to-peer lending platforms Zopa,

\footnotetext{
173 Ibid.

174 David S Evans, 'Economic Aspects of Bitcoin and Other Decentralized Public-Ledger Currency Platforms' (2014) at http://ssrn.com/abstract=2424516; Angela Walch, 'The Bitcoin Blockchain as Financial Market Infrastructure: A Consideration of Operational Risk' (2015) 18 Legislation and Public Policy 837. Marcella Atzuri, 'Blockchain Technology and Decentralized Governance: Is the State Still Necessary?' (2015) at http://ssrn.com/abstract=2731132.

175 Kelvin Low and Ernie Teo, 'Bitcoins and Other Cryptocurrencies as Property?' (2017) 9 Law Innovation and Technology 235.

176 'Blockchain's Once-Feared 51\% Attack Is Now Becoming Regular' (8 June 2018) at https://www.coindesk.com/blockchains-feared-51-attack-now-becoming-regular.

177 'How many bitcoin forks are there?' at https://forkdrop.io/how-many-bitcoin-forks-are-there; 'Ethereum Executes Blockchain Hard Fork to Return DAO Funds' (2016) at https://www.coindesk.com/ethereumexecutes-blockchain-hard-fork-return-dao-investor-funds; and attack on the already forked ethereum classic in Jan 2019, see 'Cryptocurrency Hackers Steal \$1.5m of Ethereum Classic in Rare Attack' (8 Jan 2019) at https://www.independent.co.uk/life-style/gadgets-and-tech/news/ethereum-classic-attack-cryptocurrencybitcoin-coinbase-etc-a8716986.html.

178 Dani Rodrik, 'Getting Institutions Right' (2004) at https://www.ifo.de/DocDL/dicereport204-forum2.pdf; Dani Rodrik, Arvind Subramanian and Francesco Trebbi, 'Institutions Rule: The Primacy of Institutions over Geography and Integration in Economic Development' (2004) 9 Journal of Economic Growth 131 on the importance of legal institutions such as private property rights and regulatory frameworks.
} 
Funding Circle and crowd investing platform Seedrs, are centrally coordinated by platform technology unicorns. This also means that new peer-to-peer infrastructures are introduced and maintained by new giants in the corporate economy, creating and maximising wealth in the same ethos as the corporate giants of old. ${ }^{179}$ On a more normative level, decentralised initiatives would struggle at scale as organisation ${ }^{180}$ is a phenomenon sustained by structures, ${ }^{181}$ power, ${ }^{182}$ institutions ${ }^{183}$ and values. ${ }^{184}$

The scalability of the DLT economy depends on policy choices in relation to governance structures and institutions. Commentators query if policies and laws should be reformed so that special responsibilities or liabilities are attached to DLT developers and miners who undertake to maintain the ledger. ${ }^{185}$ Blemus further queries whether DLT enterprises, which enrol token financiers to support them should become stakeholder-based eco-systems. ${ }^{186}$ Should policy choices be considered in relation to the unique corporate governance needs of DLT enterprises such as the roles of developers, the roles and rights of token financiers, relational mechanisms such as decisionmaking, accountability and dispute resolution, and crucially, distributional frameworks in relation to the wealth created on the DLT system ${ }^{187}$ The resolution of these issues can pave the way for scalable DLT to be used in the organisation of activities or transactions that are not sufficiently undertaken by the corporate economy today, such as socially-oriented endeavours or social enterprises. ${ }^{188}$

\section{Fundamental/Structural Changes Led by Al, DLT or Both}

\footnotetext{
${ }^{179}$ Roger M Barker and Iris H-Y Chiu (eds), The Law of Organisations and Governance: Decentralised Business Models and Digital Transformation (Oxford: Routledge 2021) forthcoming at ch5.

${ }^{180}$ Haridimos Tsoukas, 'Organisation as Chaosmos' in Tsoukas, Philosophical Organisation Theory (Oxford: OUP 2018) at ch1 describing organisation as generating order from disorganised or chaotic states.

181 The Weberian organisational order and the Parsonian functionalist approach to organisation, see Tuomo Peltonen, Hugo Gaggiotti and Peter Case, 'Introduction: In Search of Alternative Origins of Organizing' and Tuomo Peltonen, 'Revisiting the Sociological Origins of Organization Theory: The Forgotten Legacy of Pitirim Sorokin' in Tuomo Peltonen et al (eds), Origins of Organising (Cheltenham: Edward Elgar 2018) at x and ch2. 182 Stewart Clegg, 'Managing Organization Futures in a Changing World of Power/Knowledge' in Christian Knudsen and Haridimos Tsoukas (eds), The Oxford Handbook of Organization Theory (Oxford: OUP 2005) at ch21.

183 Douglass C North, Institutions, Institutional Change and Economic Performance (Cambridge: Cambridge University Press, 1990) at ch1.

${ }^{184}$ Amitai Etzioni, A Comparative Analysis of Complex Organisations (Glencoe: The Free Press 1961).

${ }^{185}$ Angela Walch, 'Deconstructing 'Decentralization': Exploring the Core Claim of Crypto Systems' (2019) at https://ssrn.com/abstract=3326244; Matthias Tarasiewicza, Andrew Newman, 'Cryptocurrencies as Distributed Community Experiments' in The Handbook of Digital Currencies (Elseiver 2015), ch10. See also Karen Yeung, 'Regulation by Blockchain: The Emerging Battle for Supremacy between the Code of Law and Code as Law' (2019) Modern L. Rev (forthcoming); Philipp Hacker, 'Corporate Governance for Complex Cryptocurrencies? A Framework for Stability and Decision Making in Blockchain-Based Organizations' in P Hacker et al eds, Regulating Blockchain: Techno-Social and Legal Challenges (Oxford: OUP 2019) at 16. ${ }^{186}$ Stéphane Blemus and Dominique Guegan, 'Initial Crypto-asset Offerings (ICOs), Tokenization and Corporate Governance' (University of Paris Sorbonne I Working Papers 2019) at https://centredeconomiesorbonne.univparis1.fr/.

${ }^{187}$ Roman Beck, Christoph Müller-Bloch, John Leslie King, 'Governance in the Blockchain Economy: A Framework and Research Agenda' (2018) 19 Journal of the Association for Information Systems 1020.

188 Wulf Kaal, 'Blockchain Technology and Race in Corporate America' (2019) at

http://ssrn.com/abstract_id=3071378; also Iris H-Y Chiu and Edward F Greene, 'The Marriage of Technology, Markets and Sustainable (and) Social Finance - Insights from ICO Markets for a New Regulatory Framework' (2019) 20 European Business Organisation Law Review 139.
} 
A number of commentators offer a futuristic vision of a new economy as being operated by $\mathrm{Al}$ in a manner capable of rendering human agency redundant. Bayern posits a vision where a corporate legal person is incorporated first by human agency, and then entrusted to Al to manage and operate. Humans can even withdraw as members if not incentivised to undertake corporate governance roles in monitoring and voting. ${ }^{189}$ Such Al would be programmed to serve the founder's purposes and can conclude contracts with third parties or carry out actions based on coded instructions upon fulfilment of conditions. A similar vision was posited by Petrin who envisages a 'fused' Board of management and operational capacity within an Al. ${ }^{190}$ The automation of the highest executive level functions can be supported on the basis of executive level decision-making being fully-informed, objective and consistent, ${ }^{191}$ overcoming the agency problem with shareholders. ${ }^{192}$ Shareholders no longer need to suffer from information asymmetry, for they no longer have to monitor Boards from a distance or rely on highly ineffective means of governance and control such as third party auditing and structuring of packages of executive remuneration.

This vision supposedly leads to a capitalist system on autopilot. However, wealth creation and distribution issues are unfortunately not as easily nailed down. At its logical extreme, the autopilot enterprise system described above can lead to a potentially highly unequal capitalist economic system that lacks social mobility and is ultimately not self-sustaining. This is because corporate or enterprise activity would be dominated by two classes- the capital owning class that can buy in sophisticated Al to manage corporate assets, and the technologically savvy elite that can design and produce sophisticated Al to do the same. Such domination would only give rise to incentives to exploit other resources, human or otherwise, in a competitive manner, resulting in social inequalities and sustainability problems where planetary resources are concerned.

Humans are unlikely, in this Al-controlled economic universe, to enjoy a restful and recreational existence envisaged by Silicon Valley proponents of the 'Universal Basic Income' (UBI). ${ }^{193}$ In anticipation of the fundamental/structural changes that may be brought about by 'technocapitalism', several Silicon Valley gurus have called for new social policy in the form of the UBI. The UBI is a fixed sum close to living wage that every human being should be entitled to whether or not in work, so as to mitigate the disruptions to work opportunities or life caused by the advent of Al. The UBI replaces social welfare, is regarded as a fundamental human right, and provides room for human beings to consider how to reinvent themselves in entrepreneurship, innovation or engaging in snatches of work in the new techno-economy. It can also be cynically seen as an opioid strategy to appease otherwise angry humans in economically and socially displaced situations. ${ }^{194}$ Would the UBI of about $\$ 1,500$ per month as envisaged by techno-capitalists in Silicon Valley be able to buy a way out of human capacity for critique, reflection and revolution?

The futuristic vision of Al displacement or replacement of human economic agency may be efficient in a number of ways. However, if economic agency is understood more broadly in a sociological and

\footnotetext{
${ }^{189}$ Bayern (2018); Shawn Bayern, Thomas Burri, Thomas D. Grant, Daniel M. Häusermann, Florian Möslein, Richard Williams, 'Company Law and Autonomous Systems' (2017) 9 Hastings Sci. \& Tech. L.J. 135.

190 Petrin (2019).

${ }^{191}$ Acknowledged by Enriques and Zetzsche (2019) although the piece is critical.

192 Murray et al (2019); Wulf Kaal, 'Blockchain Solutions for Agency Problems in Corporate Governance' in Kashi R. Balachandran (ed), Economic Information to Facilitate Decision Making (World Scientific Publishers, 2019).

193 'Why Silicon Valley is Embracing Universal Basic Income' (The Guardian, 22 June 2016) at https://www.theguardian.com/technology/2016/jun/22/silicon-valley-universal-basic-income-y-combinator. 194 Ibid.
} 
psychological context, ${ }^{195}$ then human agency remains relevant where $\mathrm{Al}$ is not fully sentient, and where humans have views about the structural changes brought about by techno-capitalism. It is queried how socially and politically stable such a vision can be, if it ignores the potency of sociological and political capacity on the part of human agency. Instead of merely looking at legal and institutional change to support such a techno-capitalist economy, there could be contests by legal and institutional movements to contain and govern such a techno-capitalist economy. Such movement is already emerging in the form of pressure for the ethical governance of Al, not by selfregulation as such by the tech industry, but regulation by international and collective bodies such as the OECD. ${ }^{196}$ This point will be elaborated in Sections B and C.

However, the techno-capitalist future could look more like that posited by Zovko. ${ }^{197}$ As DLT enables a flattened networked structure for economic agency, enterprisal and work opportunities could arise within such structures without being tyrannised by Al-replaced hierarchies posited above. Zovko envisages that with the advent of technological breakthroughs such as 3-D printing and the Internet of Things, it is possible for economic life to become more individually tailor-made instead of being subject to industrialised and corporatized work patterns. We can become ad hoc entrepreneurs of 3D printed products and designs on demand, while occasionally earning by giving others a Lyft or letting out the spare bedroom on AirBnB. Economic agency becomes 'prosumerist', multifaceted and tailor-made, while work, play and social interaction can all become on-demand, networked, virtual as well as real, and fused. In this manner, the industrialised worklife, contracted employment and the corporate model of mass production and wealth creation may all be fundamentally shaken up. ${ }^{198}$

Much economic life could be managed by tokenisation on ledger-based economies, and humans can become fused biologically with aspects of Al in order to manage their economic, social, political etc. agency. The forces that propel towards economic domination as painted in the previous picture will be equally matched by the forces that propel towards disintermediation and new forms of economic mobilisation and empowerment.

As we tokenise the spare seat at our dinner table, should we be faced with hygiene and food regulations? Should our paying dinner guest be able to sue for a stomach upset? How will peer-topeer economies change allocations of private law duties, rights and liabilities? ${ }^{199}$ Or should we all subscribe to insurance tokens that clearly delineate risks and costs in an ex ante manner so that we can dip in and out of different economic agencies at ease? Will we see a rise in regulation for ex ante risk distribution in a movement from 'tort to regulation'? ${ }^{200}$ Ultimately, will new bottom-up developments of governance unique to such networked economies provide the working norms for such economies and displace general legal paradigms?

\footnotetext{
195 see literature from economic sociologists and those that deal with microfoundations of economic action beyond incentives, Mark Granovetter, 'Economic Action and Social Structure: The Problem of Embeddedness' (1985) 91 American Journal of Sociology 481 on the social embeddedness of economic activities, Jens Beckert, 'Re-imagining Capitalist Dynamics: Fictional Expectations and the Openness of Economic Futures', Victor Nee and Sonja Opper, 'Economic Institutions from Networks' and Nina Bendelj, 'Thinking about Social Relations in Economy as Relational Work' in Patrik Aspers and Nigel Dodd (eds), Reimagining Economic Sociology (Oxford: OUP 2015), ch3, 7 and 10.

${ }^{196}$ OECD Principles on Artificial Intelligence at https://www.oecd.org/going-digital/ai/principles/.

197 Zovko (2018).

198 'Robots in the Boardroom and Other Technology Tipping Points' (Targeted News Service 9 Sep 2015).

199 Bayern (2018); Ryan Calo, 'Robotics and the Lessons of Cyberlaw' (2015), 103 Calif. L. Rev. 513-63 at 554-5 queries whether ex ante distributions of risk will be more pronounced.)

200 Jackson (2019), and see quote in Brownsword (2019) at 184.
} 
Changes to laws and institutions are not merely reactive but also proactive, as policy choices can be made to cope with new activities as well as to facilitate and govern them. ${ }^{201}$ The pressure for new freedoms and clarification of uncertainties, and the need to ensure that institutions can withstand the test of time (the rhetoric regarding technological neutrality ${ }^{202}$ favoured by the European Commission for example) will represent different waves of pressure compelling institutional responses. One commentator sees the scale of legal and institutional change as likely to become significant- affecting many 'established' domains such as employment law, consumer law, product liability, intellectual property and competition laws. ${ }^{203}$

Moreover, Fenwick et $\mathrm{al}^{204}$ champion the development of platform governance, where systems of order are co-generated by all stakeholders of a platform. Although they write in the context of the platform economy, these insights are applicable to the DLT business platform which is also distributed and networked. The rise of platform governance can bring about institutional replacements for existing legal and governance norms, such as for the corporate economy. Private laws of organisations and transactions, as well as public regulatory institutions for economic life, both come under challenge in terms of relevance and adjustment. ${ }^{205}$ We may also see new combinations of co-regulatory partnerships between private and public sector actors, as Finck proposes, ${ }^{206}$ to shape the generation of norms and policies for the flattened and networked economy.

All the scenarios discussed in radical/disruptive or fundamental/structural CorpTech suggest that institutional responses would be necessary to cope with, govern, permit, facilitate or restrict new configurations in economic agency and governance structures and the rise of new entities, legal conceptualisations and institutions of economic life. Policy choices, however, still have to be made in relation to old normative questions. We use the term 'policy choice' in a broad manner encompassing lawmakers' and regulators' choices, as well as collective social choices that could have the effect of soft law. These old normative questions relate to the allocation of power and rights ${ }^{207}$ as well as regulators' roles in safeguarding the social commons. ${ }^{208}$ These old normative questions remain whether we look at society as being physically bounded in geography or as existing in virtual communities.

\footnotetext{
201 Barak Orbach, 'What is Regulation?' (2012) 30 Yale Journal on Regulation Online 1.)

202 Rory Copeland, 'FCA Final Guidance on Cryptoassets: jettisoning tech-neutrality?' (2019) at https://www.law.ox.ac.uk/business-law-blog/blog/2019/09/fca-final-guidance-cryptoassets-jettisoning-techneutrality.

203 Barfield (2018).

${ }^{204}$ Mark Fenwick, Wulf A Kaal and Erik PM Vermeulen, 'The “Unmediated" and "Tech-driven" Corporate Governance of Today's Winning Companies' (2017) at https://ssrn.com/abstract=2922176; Mark Fenwick, Joseph A McCahery and Erik PM Vermeulen, 'The End of Corporate Governance: Hello Platform Governance' (2018) at http://ssrn.com/abstract_id=3232663.

205 Brownsword argues that, '... the destiny of legal rules is to be found somewhere in the range of redundancy, replacement, redirection, revision and refinement', (2019) at 181.

206 Finck (2017).

207 Including being articulated through law.

208 Brownsword (2019), at chs 1-4, and ch5, 6 and 8, at 191-202 on how legal and regulatory institutions could respond to technological change. These institutions would be caught between interpreting technology changes within the needs of coherence and social stability while responding to new needs in allocating responsibility and rights in order to achieve goals such as public safety and protection from harm. Old normative questions are themselves contested (e.g. see the discussion in ch5 on the nature of the rule of law and its disconnection from particular substantive norms) and solutions addressing them are far from clear or consensual.
} 
We turn now to Section B which argues that policy choices for old normative questions will be made within an institutional paradigm. Section B explores the institutional theoretical framework and Section $\mathrm{C}$ applies this framework to predict the extent of institutional change that will entail in response to CorpTech.

\section{B. An Institutional Theory of Corporate Law Reform}

In this Section, we construct a multi-theoretical framework for mapping policy choices in view of technological change. This multi-theoretical framework extrapolates in greater detail the perspective of 'deep normative structures' articulated by Eidenmüller. ${ }^{209}$ Eidenmüller argues that technological revolutions are mediated by a society's 'deep normative structures' at any given time when making policy choices. These policy choices are not dictated by technological functionalities or efficiencydriven economic perspectives alone.

First, we consider how institutional change may be brought about by technological change. Our review of theoretical literature in this area distils the key drivers that support institutional change in response to technological changes. Next, we review theoretical literature on corporate law and governance reform, and distil the key factors for corporate law evolution. Both sets of reviews can be integrated to analytically derive an institutionally-based, multi-theoretical framework for predicting change in corporate law and governance in response to technological change.

\section{Theoretical Drivers for Institutional Change in Response to Technological Change}

Institutions can be thought of as formal and informal rules, norms, patterns, forms, systems, ceremonies or even rituals through which human interactions or relations are stabilised in terms of expectations and conduct. ${ }^{210}$

Commentators are generally of the view that technological change, which relates to functionality and the 'material world', is not deterministic of institutional change. ${ }^{211}$ Institutions are social creations, and change is socially embedded ${ }^{212}$ and mediated. ${ }^{213}$ In this broad universe of social sense-making of technological change, institutional change is generally preceded by 'ideological' change. North defines 'ideology' as a 'short-cut' device for making sense of the world, through a stabilised 'world view'. ${ }^{214}$ Hence, institutional change requires a collective and cognitive change of world view. This change of world view goes through a process of stabilisation in social opinion and response, and ultimately to legitimation, possibly through changes to law and policy. ${ }^{215}$ From ideological change to the process of social absorption and acceptance, institutional change is socially determined as it relates first to social cognition and then to enactment in rules, norms, patterns,

\footnotetext{
${ }^{210}$ Horst Eidenmüller, 'Machine Performance and Human Failure: How Shall We Regulate Autonomous Machines?' (2019) at http://ssrn.com/abstract=3414602.

${ }^{210}$ Douglass C North, Institutions, Institutional Change and Economic Performance (Cambridge: Cambridge University Press, 1990) at ch1.

${ }^{211}$ Eidenmüller (2019); Peter Lindseth, 'Technology, Democracy, and Institutional Change' in Colette Cuijpers, Corien Prins, Peter Lindseth and Monica Rosina (eds), Digital Democracy in a Globalised World (Edward Elgar 2017) at ch16.

${ }^{212}$ Granovetter (1985).

${ }^{213}$ Jannis Kallinikos, Hans Hasselbladh and Attila Marton, 'Governing Social Practice: Technology and Institutional Change' (2013) 42 Theory and Society 395; Shiping Tang, A General Theory of Institutional Change (Oxford: Routledge 2017) at ch3.

${ }^{214}$ North (1990).

${ }^{215}$ Tang (2017).
} 
systems, rituals, ceremonies, habits or other artifacts of social life. ${ }^{216}$ In sum, social capital and its mobilisation are key to institutional change. The social determinants include (a) the impact of power structures and incentives; (b) bottom-up structures; (c) organisational mediation; (d) government or policy leadership and (e) temporal conditions. We survey these below.

\section{(a) Impact of power structures and incentives}

North argues that institutional change is generally slow and 'sticky' as existing institutions reflect power allocations in politics and society. Powerful interest groups have incentives to defend their hold on power as reinforced by extant institutions. ${ }^{217}$ Bebchuk and Roe also argue that power allocations tend to be entrenched because existing institutions affect the incentives and resources of corporate actors to choose and implement corporate rules. ${ }^{218}$ For example, controlling shareholders will have the incentive to maintain the existing rules that favour them and oppose proposed rules that disadvantage them. ${ }^{219}$ Another example is corporate insiders who have the incentive and ability to deploy corporate assets to lobby politicians in order to extract private benefits of control. ${ }^{220} \mathrm{It}$ is also questionable whether CorpTech will seriously subvert the powers and incentives of the interest groups, particularly governments who own and control state-owned enterprises (SOEs) in authoritarian or autocratic states. An argument can be made that the Chinese government, as the controller of SOEs, has used Al to further its anti-democratic ends. ${ }^{221}$

However, it may be argued that entrenched interests may not always prevent new power clusters from arising, as market-based forces can generate new elites, such as the new technological elite of today. Economic, social or political disturbances can result in new power shifts and reconfigurations, ${ }^{222}$ particularly in facilitative legal cultures where legal institutions envisage the enabling of economic activities. ${ }^{223}$ Nevertheless, these new technological elites such as FaceBook and Amazon in the US or Alibaba, Baidu and TenCent in China are companies controlled by

\footnotetext{
${ }^{216}$ Lindseth (2017); Kallinikos et al (2013); R Rajao \& N Hayes 'Conceptions of Control and IT Artefacts: An Institutional Account of the Amazon Rainforest Monitoring System' (2009) Journal of Information Technology 24; J Runde, M Jones, K Munir, \& L Nikolychuk, ' On Technological Objects and the Adoption of Technological Product Innovations: Rules, Routines and the Transition from Analogue Photography to Digital Imaging' (2009) Cambridge Journal of Economics 55.

${ }^{217}$ North (1990).

${ }^{218}$ Lucian A Bebchuk and Mark J. Roe, 'A Theory of Path Dependence in Corporate Ownership and Governance' (1999) 52 Stanford Law Review 127 at 157-160 219 lbid..

${ }^{220}$ Lucian A Bebchuk and Zvika Neeman, 'Investor Protection and Interest Group Politics' (2010) 23 Review of Financial Studies 1089.

${ }^{221}$ For example, the state as the controlling shareholder of state-owned enterprises in autocratic states such as China has used Al to threaten and even violate human rights. The government has worked with private companies and SOEs to produce and use AI-powered facial recognition system to curtail the rights and liberties of Uighurs. The SOEs have partnered with private companies to develop an Al social credit system that collects data on individuals' financial and social history and transactions with a view to controlling and exposing their behavior. Kyle Matthews \& Alexandrine Royer, "Artificial Intelligence Has Been Weaponized in China. That Should Be a Wake-Up Call for the World" CBC News (21 May 2019); Ryan Daws, "US Adds Chinese Al Firms to Ban List Citing Abuses Against Muslims in Xinjiang" AI News (8 Oct 2019). For a list of the Chinese SOEs and private companies that have been blacklisted by the US government, see https://s3.amazonaws.com/publicinspection.federalregister.gov/2019-22210.pdf.

${ }^{222}$ specifically discussed in relation to corporate law and governance change shortly.

${ }^{223}$ Lynne Kiesling and David Chassin, 'Decentralized Coordination Through Digital Technology, Dynamic Pricing, and Customer-Driven Control: The Gridwise Testbed Demonstration Project' (2008) 21 Electricity Journal 51; (2009) at http://ssrn.com/abstract=1417580; Katharina Pistor, Yoram Keinan, Jan Kleinheisterkamp, and Mark D. West, 'Innovation in Corporate Law' (2003) 31 Journal of Comparative Economics 676.
} 
controlling shareholders and their interests and powers are entrenched in alignment with existing institutions.

(b) Bottom up structures

Top down power structures tell only part of the story. The 'social capital' needed for institutional change driven by technological change is often not incentive-based alone, but galvanised in collective contexts of human discourse and interaction. Commentators mostly agree that institutional change is socially mediated and enacted, ${ }^{224}$ and how society makes sense of and applies the technological introduction to social lives is most important in determining whether technological change will experience social endorsement and diffusion. Thus, social capital can be found in 'bottom-up' paradigms, where social relationships and networks galvanise and accelerate such social capital. ${ }^{225}$ Indeed, technological revolutions in social networks such as social media has increased the channels for social diffusion.

\section{(c) Organisational mediation}

Further, much of social capital can be found in organisational mediation of technological change, as business and the workplace are at the forefront of navigating technological change. Fountain's work ${ }^{226}$ provides insight into how organisational structures and culture are built upon organisational relationships, norms and values, and asserts that technological change is often mediated within these relationships. Institutional change is often the result of organisational adoption of technological change where relationships and values are reinforced (more than disrupted) by such change. Kalinikos ${ }^{227}$ argues that even where technological change results in 'disembedding' effects for organisational structures and norms, new configurations of organisational structures must still cohere with the social fabric.

(d) Government or policy leadership

One may question whether government-led leadership into innovation is key to institutional change. Surprisingly, empirical research from China indicates that top-down policy in driving innovation per se does not guarantee institutional change where incentives are not yet compatible. ${ }^{228}$ Hence, policy alone cannot foster the conditions for social capital that support institutional change. Indeed, it has been argued that government or policy leadership in innovation is more likely to result in institutional change only if such innovation is successfully commercialised. ${ }^{229}$ Social endorsement of the technological change by markets and society is crucial to institutional change.

(e) Temporal conditions

\footnotetext{
${ }^{224}$ Kallinikos et al (2013); Jane Fountain, Building a Virtual State: Information Technology and Institutional Change (Brookings Institution 2001); Tang (2017).

${ }^{225}$ Norman Clark, B Yoganan and Andy Hall, 'New Science, Capacity Development and Institutional Change' (2002) 1 IJTMSD 196.

${ }^{226}$ Fountain (2001).

227 Jannis Kallinikos, The Consequences of Information: Institutional Implications of Technological Change (Cheltenham: Edward Elgar 2017) at ch 1.

${ }^{228}$ Mingzhi Li and Kai Reimers, 'Government Driven Model of Institutional Change Through Adoption of New Technology: A Case Study of the Failed Pharmaceutical Bidding and Procurement Platforms in China' (2012) 6 Chinese Management Studies 53.

${ }^{229}$ Ronnie J Philips, 'Digital Technology and Institutional Change from the Gilded Age to Modern Times: The Impact of the Telegraph and the Internet' (2000) 34 Journal of Economic Issues 266; Rahul Mukerji, 'Interests, Wireless Technology, and Institutional Change: From Government Monopoly to Regulated Competition in Indian Telecommunications' (2009) 68 Journal of Asian Studies 491.
} 
Finally, temporal conditions affect the social response to technological change. As argued by lyigun and Rubin, ${ }^{230}$ the state of society at a given time affects its response to new technology, such as whether society is generally experiencing stability or upheaval/trauma such as natural or social disasters (and not technologically-led events). The research finds that stable societies or 'peacetime' conditions are conducive to a social mood of being willing to experiment with, accept and invest in technological change for the future. However, if a society experiences upheaval such as a significant natural disaster or social divisions and disturbances, then the social mood for absorbing and investing in change is scarce, as risk aversion typifies the mood of such societies. Such risk aversion would also drive society to prefer traditional values and paradigms that seem more familiar and comfortable, giving rise to resistance against technological and institutional change.

We turn now to exploring what drives corporate law and governance changes generally before deriving a combined theoretic framework.

\section{Theoretical Drivers for Change in Corporate Law and Governance}

Corporate law and governance in many jurisdictions stand at an interface of contesting ideologies, such as shareholder primacy, director primacy (or managerial capitalism) and stakeholder-based or communitarian ideologies. ${ }^{231}$ The waxing and waning of ideological trends support corporate law and governance reform. There are, however, underlying drivers for such ideological tides, and we observe a narrow circle of 'social capital mobilisation' that drive such ideological tides in different times. This narrow circle has centred upon key political economy actors such as shareholders and directors in liberal market economies, labour in coordinated market economies such as Germany and Japan, and the state in state-oriented economies such as China, Singapore and South Korea.

\section{Shareholder primacy and minority shareholder protection}

The shareholder primacy ideology is rooted in two different traditions although it is frequently said to characterise the corporate law of liberal market economies like the US and UK. ${ }^{232}$ In the UK, the legal preference for shareholder centricity is a legacy issue, as businesses transformed into corporations from the late $19^{\text {th }}$ century, bringing partnership concepts into company law. ${ }^{233}$ Partnerships are formed by individuals who are both capital and management providers and the fusion of ownership and control in many family-owned companies in the UK was the context for a company law that provided (and continues to provide) significantly for shareholders' rights in corporate decision-making. ${ }^{234}$ This system of power allocation and accountability that favours shareholders has persisted in the UK even though businesses in the UK have embraced separation of

\footnotetext{
${ }^{230}$ Murat Iyigun and Jared Rubin, 'The Ideological Roots of Institutional Change' (2017) at http://ssrn.com/abstract=2960492.

${ }^{231}$ Grietje Baars ed, The Corporation (Cambridge University Press, 2017) generally; Lyman Johnson, 'Corporate Law and the History of Corporate Social Responsibility' (2017) at http://ssrn.com/abstract=2962432.

232 Peter A Hall and David Soskice, 'An Introduction to Varieties of Capitalism' in Peter A Hall and David Soskice (eds), Varieties of Capitalism: The Institutional Foundations of Comparative Advantage (Oxford: Oxford University Press 2001) at ch1.

${ }^{233}$ Paddy Ireland, 'Limited liability, Shareholder Rights and the Problem of Corporate Irresponsibility' (2010) 34 Cambridge Journal of Economics 837.

${ }^{234}$ For example, shareholders determine and can amend the corporate constitution, s21, UK Companies Act 2006; much of company law in terms of internal governance is enabling in nature, such as the possibility of opting out of the enabling default 'constitution' set out in the Model Articles Regulations, and the Foss $v$ Harbottle doctrine that looks to shareholders to ratify internal breaches or errors before resorting to derivative actions, s239. The general meeting has powers to scrutinise substantial transactions, executive pay and to remove any director by an ordinary resolution, see s199ff; s439A and s168.
} 
ownership from control from the post-war period. ${ }^{235}$ In the same manner, the primacy of shareholders in common law Asian countries is a strong tenet, although the corporate ownership structures are very different as they are usually characterised by concentrated family or state ownership of companies. ${ }^{236}$

Shareholder-centric company law is further supported by economic ideology, whose qualities of objectivity and neutrality stand in contrast to tradition. However, ideological reinforcement for tradition has taken place as new shareholder actors have aligned interests and champion the same mantle. The ideology of shareholder primacy accelerated in the 1970s with the rise of economic theories for corporate organisation, ${ }^{237}$ seemingly providing an objective and not power-centred basis for shareholder primacy. This arose largely in the US but has become an ideological foundation for theories of corporate governance, driving much international convergence. ${ }^{238}$ Economic efficiency theories of organisation frame corporations as voluntary organisations that house a 'nexus of contracts' to organise resources for production, ${ }^{239}$ and shareholders as 'residual claimants' that provide the bedrock of stable capital for corporate exploitation. ${ }^{240}$ The key theoretical issue in corporate governance, which is the allocation of power and decision-making in corporations, ${ }^{241}$ creates the agency problem - - how to address the possible diversion of interest between managers who manage shareholders' capital and shareholders who are residual claimants. ${ }^{242}$

The rise of institutional shareholders worldwide is the power context that supports shareholder primacy as the dominant ideology in corporate law. As private savings and investment rose in the wake of the retreat of State welfare after the Second World War, giving rise to the growth of the investment intermediation and asset management sector, this new set of financial sector actors has become key owners of global equities. The rise of institutional investors would not fundamentally shake up shareholder-centric ideology, ${ }^{243}$ as their incentives remain aligned with that fundamental bedrock. However, institutional investors, who are usually minority shareholders, champion a

\footnotetext{
235 Dispersed ownership only started taking off from the post-War period, hence company law served the needs of closely-held companies, Brian Cheffins, Corporate Ownership and Control: British Business Transformed (Oxford: OUP 2008).

${ }^{236}$ Ernest Lim, A Case for Shareholders' Fiduciary Duties in Common Law Asia (Cambridge: CUP 2019).

237 To be enumerated.

238 International convergence is driven by institutional investors in global capital markets, Paul Davies and Klaus J Hopt, 'Boards in Europe: Accountability and Convergence' (2013) 61 American Journal of Comparative Law 301; Mathias Siems, 'Convergence in Corporate Governance: A Leximetric Approach' (2010) 35 Journal of Corporation Law 729; Carsten Gerner-Beuerle, 'Determinants of Corporate Governance Codes' (2014) at http://papers.ssrn.com/sol3/papers.cfm?abstract_id=2346673. Policies introduced by international financial institutions such as the IMF and the World Bank in their lending programmes often makes corporate governance reform essential, in the mould of Anglo-American corporate governance norms.

${ }^{239}$ Ronald Coase, 'The Nature of the Firm' (1937) 4(16) Economica 386-405.

${ }^{240}$ Armen Alchian and Harold Demsetz, "Production, Information Costs and Economic Organisation" (1972) 62 The American Economic Rev 777. See also Oliver Williamson, "Corporate Governance" (1984) 93 Yale Law Journal 1197.

241 Defined by the OECD, 'Corporate governance involves a set of relationships between a company's management, its board, its shareholders and other stakeholders. Corporate governance also provides the structure through which the objectives of the company are set, and the means of attaining those objectives and monitoring performance are determined', p9, G20/OCED Principles of Corporate Governance (2015) at https://www.oecd.org/daf/ca/Corporate-Governance-Principles-ENG.pdf.

242 Michael C Jensen and William H Meckling, "Theory of the Firm: Managerial Behaviour, Agency Costs and Ownership Structure" (1976) 3 Journal of Financial Economics 305.

243 Richard C Nolan, 'The Continuing Evolution of Shareholder Governance' (2006) 65 Cambridge Law Journal 92.
} 
slightly different type of shareholder centricity, which focuses on minority shareholder protection, and find ideological resonance in the law and finance school of thought.

Since the late 1990s, the beginning of globalisation has heralded an introduction to liberation in capital markets, ${ }^{244}$ stimulating comparative research into the growth and success of capital markets around the world. ${ }^{245}$ In finding the salient factors that would promote capital flows into any particular jurisdiction, encourage investment in that jurisdiction's listed companies and attract companies to list in that jurisdiction, commentators have found that 'law matters'. ${ }^{246}$ This means that a jurisdiction's corporate laws and laws relating to its securities markets are game-changing factors for the attractiveness of its capital markets, the development of which benefits the corporate economy and economic development generally. ${ }^{247}$ This 'law and finance' research strand has produced influential policy proposals internationally, encouraging jurisdictions to provide for minority shareholder protection laws that are positively regarded by the institutional shareholder community which commands trillions of pooled fund moneys for global investment. ${ }^{248}$ Such ideology is also favoured by European policy makers ${ }^{249}$ focused on building a single and strong European capital market, leading to the adoption of policies that subscribe to shareholder-focused corporate laws and governance ${ }^{250}$ norms. Such ideology has to be navigated within political economy contexts such as Germany's and commentators remark how German corporate law institutions have changed even if the Anglo-American introductions are implemented with national flavour. ${ }^{251}$ Further, the prominority shareholder ideology has profoundly influenced institutional change in jurisdictions with shareholder-centric corporate laws that nevertheless served controlling shareholders. The mobilisation of the shareholder primacy ${ }^{252}$ and 'law and finance' ideology has found favour with policy-makers who see such policy choice in favour of regulatory competition. ${ }^{253}$

\section{Shareholders v management and the political economy}

\footnotetext{
244 John Williamson and Molly Mahar, A Review of Financial Liberalization (World Bank, Washington,1998).

${ }^{245}$ Such as Rafael La Porta, Florencio Lopez-de-Silanes, Andrei Shleifer and Robert Vishny, 'Law and Finance' (1998) 106 Journal of Political Economy 1113; Rafael La Porta, Florencio Lopez-de-Silanes and Andrei Shleifer, 'What Works in Securities Laws' (2006) 71 Journal of Finance 1.

${ }^{246}$ Above, and John C Coffee, 'Law and the Markets- The Impact of Enforcement' (2007) 156 University of Pennsylvania Law Review 229; Amir Licht, 'Cross-Listing and Corporate Governance: Bonding or Avoiding?' (2003) 4 Chicago Journal of International Law 141.

${ }^{247}$ Carsten Gerner-Beurle, 'Law and Finance in Emerging Economies: Germany and Britain 1800-1913' (2017) 80 Modern Law Review 263.

${ }^{248}$ Roger M Barker and Iris H-Y Chiu, Investment Management and Corporate Governance (Cheltenham: Edward Elgar 2017) at ch1.

${ }^{249}$ Gregory Jackson \& Arndt Sorge, 'The Trajectory of Institutional Change in Germany, 1979-2009' (2012) 19 Journal of European Public Policy 1146-1167.

250 Shareholders Rights Directives 2007 and 2016 are aimed at making it easier and empowering institutional shareholders to engage and vote.

${ }^{251}$ Adam Winkler, 'Corporate Law or the Law of Business?' (2004) 67 Law and Contemporary Problems 109; Dalia Tsuk, 'Corporations Without Labor: The Politics of Progressive Corporate Law' (2003) 151 U. Pa. L. Rev. 1861; Iris H-Y Chiu, 'An Institutional Theory of Corporate Regulation' (2018) 71 Current Legal Problems 279. 252 Henry H Hansmann and Reiner H Kraakman, 'The End of History for Corporate Law' (2000) 89 Georgetown Law Journal 439.

253 Peter Gourevitch, 'Politics and Corporate Governance: What Explains Policy Outcomes?' in Greg Urban (ed), Corporations and Citizenship (University of Pennsylvania Press 2014); Gregory Schaffer, 'Law and Business' in David Coen, Wyn Grant and Graham Wilson (eds), The Oxford Handbook of Business and Government (Oxford: OUP, 2010). For a Japanese take, Hatsuru Morita, 'Corporate Law Reform and the Political Environment: An Empirical Analysis Employing Public-Comment Procedure Data in Japan' (2017) 4 Asian Journal of Law and Society 309.
} 
A concurrent movement in power configuration and ideological contest has however been afoot in the US and UK since the post-war period. This relates to the rise of professional managers. With increasing separation of ownership from control in corporations, a new and powerful class of the managerial elite has come about, and they may not be shareholders at the same time.

The managerial class could spearhead a different ideology that centralises them, not shareholders, in corporate governance, such that shareholders would become just another group of constituents to manage. The main contest in jurisdictions that experience separation of ownership and control is thus between shareholder and director primacy.

The corporate laws of the US and UK bear many hallmarks of the ideological contest between shareholder and director primacy. In the US, although shareholder primacy is endorsed in the Michigan court as the primary purpose of corporations, ${ }^{254}$ control of corporate decision-making by managers, who were not the same persons as shareholders, was the de facto reality in the US. ${ }^{255}$ The managerial class grew in power, giving rise to an era of managerial capitalism ${ }^{256}$ which is reflected in Delaware corporate law, such as directorial primacy doctrines in relation to decisions of corporate control. ${ }^{257}$ Hence, there is a strong ideological strand in the US favouring director primacy ${ }^{258}$ and the perspective that directors are professional stewards of corporate resources who can balance the interests of all stakeholders in their ultimate pursuit of the well-being of the corporation as its own legal entity. ${ }^{259}$ The UK also accepts the corporation as its own legal person, with the entity theory having as long a tradition as shareholder-centred corporate law. ${ }^{260} \mathrm{Hence}$, 'shareholder primacy' is not the only ideological characteristic of UK corporate law.

The power balance between the capital and managerial classes in jurisdictions where ownership and control are largely separated provides the context for mobilising ideological trends and their influence upon institutional change. Hence, in the UK, corporate law reforms towards empowering

\footnotetext{
${ }^{254}$ Dodge v. Ford Motor Company, 204 Mich. 459, 170 N.W. 668 (Mich. 1919), Jonathan R Macey, 'A Close Read of an Excellent Commentary on Dodge v Ford' (2008) 3 Virginia Business and Law Review 177.

255 Powers in the hands of corporate managers was a subject of concern in Adolf A Berle, Gardiner C Means, The Modern Corporation and Private Property (1932; Transaction Publishers, 1991 Rep); and the Berle-Dodd debate in E Merrick Dodd, 'For Whom are Corporate Managers Trustees?' (1932) 45 Harvard Law Review 114563.

${ }^{256}$ Alfred D Chandler, 'The Emergence of Managerial Capitalism' (1984) 58 Business History Review 473; Peter F Drucker, Concept of a Corporation (John Day, 1946).

${ }^{257}$ Bebchuk points out that, compared to their UK counterparts, shareholders in Delaware-incorporated companies do not have the right to propose Charter amendments and are excluded from game-ending and corporate restructuring decisions. Further, Delaware upholds the right of management to defend vigorously against takeovers by means of poison pills so that the market for corporate control is muted in its disciplinary effect, Lucian Ayre Bebchuk, 'The Case for Increasing Shareholder Power' (2005) 118 Harvard Law Review 833; Lucian Ayre Bebchuk and Allen Ferrell, 'On Takeover Law and Regulatory Competition' (2002) 57 Business Lawyer 1047.

${ }^{258}$ Christopher M Bruner, Corporate Governance in the Common Law World (Cambridge: Cambridge University Press, 2013).

${ }^{259}$ Supporters of director primacy include Margaret Blair and Lynn Stout, "A Team Production Theory of Corporate Law" (1999) 85 Virginia Law Review 248; Stephen M Bainbridge, 'Director Primacy and Shareholder Disempowerment' (2006) 199 Harvard Law Review 1735; Lynn Stout, The Shareholder Value Myth: How Putting Shareholders First Harms Investors, Corporations, and the Public (Berrett-Koehler, 2012).

260 Directors' duties are owed to the corporation as its own entity as distinguished from the body of shareholders or individual shareholders, Peskin v Anderson [2000] EWCA Civ 326. Also see Andrew Keay, The Corporate Objective (Cheltenham: Edward Elgar, 2010); 'Ascertaining the Corporate Objective: An Entity Maximisation and Sustainability Model' (2008) at http://papers.ssrn.com/sol3/papers.cfm?abstract_id=1889236.
} 
shareholders are often introduced after corporate scandals which involve wrong-doing management. ${ }^{261}$ However, this is often balanced by concurrent reforms that target management and seek to make management more robust, such as the introduction of the independent director institution in the UK ${ }^{262}$ and the internal control regulations under the US Sarbanes-Oxley Act 2002 after the fall of Enron. ${ }^{263}$ In other jurisdictions with a different political economy, the larger picture is similar in that corporate law is borne out of the power balances achieved in the political economy.

\section{Shareholders v stakeholders}

It is argued that the ideology of stakeholder or communitarian types of corporate capitalism are reflected in coordinated market economies like Germany ${ }^{264}$ and Japan, although post-war occupation by the US also introduced significant changes to their corporate law and governance arrangements. ${ }^{265}$ The corporate laws and governance arrangements in these economies reflect communitarian economic bargains, such as those made between labour and capital, and culminate in institutions of corporate governance such as co-determination, the representation of workers on corporate Boards in Germany, ${ }^{266}$ and the entrenched nature of the Japanese managerial class who are sourced from long-term employees. ${ }^{267}$

\section{The state as the shareholder}

The stakeholder or communitarian ideologies are also reflected in state-oriented economies such as China, India, and Singapore, albeit in a different form from the coordinated market economies like Germany and Japan. ${ }^{268} \mathrm{~A}$ central feature of the corporate governance system in these economies is that the state is the controlling shareholder of a significant percentage of companies, often known as state-owned enterprises (SOEs). ${ }^{269}$ Being the controller, it often exerts direct or indirect control over the management of the company. These SOEs have public-oriented, socio-economic objectives such as the production and supply of key public services and goods, the generation of employment and the equitable distribution of resources. ${ }^{270}$ Consequently, the managers of the SOEs in these state-oriented economies are given more latitude than the companies in liberal market economies

\footnotetext{
${ }^{261}$ For example, the call for shareholder scrutiny of corporate governance practices is based on the first Cadbury Code of Corporate Governance after the corporate failures of Polly Peck and $\mathrm{BCCl}$ in the UK; and the introduction of the Stewardship Code for shareholders in the UK in 2010 after the global financial crisis 2007-9. ${ }^{262}$ First introduced in the Cadbury Code, ibid. This institution has only been strengthened over the years, as evidenced in the increase in independent Board composition to 50\%, Provision 11, UK Corporate Governance Code 2018; the role of the independent director in premium listed companies on the London Stock Exchange with controlling shareholders, see UK Financial Conduct Authority Listing Rules 9.8.4A.

263 Sections 301, 302 for example.

${ }^{264}$ Sigurt Vitols, 'Varieties of Corporate Governance: Comparing Germany and the UK' in in Peter A Hall and David Soskice (eds), Varieties of Capitalism: The Institutional Foundations of Comparative Advantage (Oxford: Oxford University Press 2001) at ch10.

${ }^{265}$ Curtis J Milhaupt, 'A Lost Decade for Japanese Corporate Governance Reform?: What's Changed, What Hasn't, and Why' (2003) at http://ssrn.com/abstract=442960.

${ }^{266}$ Stephen C Smith, 'On the Economic Rationale for Codetermination Law' (1991) 16 Journal of Economic Behavior \& Organization 261.

267 Milhaupt (2003).

268 Nahee Kang and Jeremy Moon, "Institutional Complementarity Between Corporate Governance and Corporate Social Responsibility: a Comparative Institutional Analysis of Three Capitalisms" (2012) 10 SocioEconomic Review (2012) 85.

269 Michael A Witt and Gordon Redding (eds.), The Oxford Handbook of Asian Business Systems (Oxford University Press 2014); Mike Wright et al. (eds), Oxford Handbook on State Capitalism and the Firm (Oxford University Press, forthcoming).

${ }^{270}$ Ernest Lim, Sustainability and Corporate Mechanisms in Asia (Cambridge University Press, 2020).
} 
to pursue objectives that are not driven by shareholder value maximisation, as long as their actions are consistent with the state's developmental, and hence, communitarian goals. ${ }^{271}$ However, the objectives of these SOEs are distinguishable from the companies in the coordinated market economies. In the latter, the interests of labour are accorded due protection in the form of codetermination in Germany and the appointment of employees as managers in Japan. By contrast, in state-oriented economies, labour rights are generally attenuated as labour unions in China and Singapore are de facto organs of the state. ${ }^{272}$. The government can exert short-term pressure on management as well as on labour by curbing the rights of employees (in contrast to employees in liberal and coordinated market economies).

Political economy contexts for corporate law and governance are fundamentally important to ideological mobilisation and institutional culmination. ${ }^{273}$ However, these contexts are not stable and are shifting. Since the millennium, significant corporate scandals have rocked social confidence in the corporate economy, and have caused social discourse to penetrate the narrow power circle of policy influence in corporate law. This has resulted in corporate law and regulatory reform of a new nature.

\section{Other social penetration into corporate law}

Corporate law and governance reform is largely mobilised by incentive-based ideology reinforcing the interests of powerful groups in the political economy. However, since the 1990s, social discourse has become increasingly relevant though yet insignificant in shaping institutional reform. ${ }^{274}$ Social discourse about corporations does not significantly influence corporate law policy unless moments of corporate scandal or disrepute provide points of inflection. ${ }^{275}$ In the 1990s, the corporate failures of Polly Peck and $\mathrm{BCCl}$ in the UK led to reform by way of a set of corporate governance best practice ${ }^{276}$ being introduced, which have since been adopted by the London Stock Exchange as part of its premium listing requirements. ${ }^{277}$ This industry-generated solution represented a gradual step towards the healing of social confidence without severe disruption to business. Similarly, in the early 2000s, the American energy giant Enron's collapse resulted in severe criticism of corporate governance norms and consequent reform. But such reform is incremental in nature, such as the mandatory audit committee for listed companies and the Chief Financial Officer's role in certifying audit integrity. These reforms ultimately looked to the self-healing capacities of the corporation to

\footnotetext{
${ }^{271}$ Howard Gospel and Andrew Pendleton (eds), Corporate Governance and Labour Management: An International Comparison (Oxford University Press, 2005).

$272 \operatorname{Lim}(2020)$.

273 Mark J Roe, The Political Determinants of Corporate Governance (Oxford: OUP 2002, 2006); Marianna Belloc and Ugo Pagano, 'Co-Evolution Paths of Politics, Technology and Corporate Governance' (ECGI Working Paper 2005) at http://ssrn.com/abstract=729725; Roberta Romano, 'Metapolitics and Corporate Law Reform' (1984) 36 Stanford Law Review 923.

${ }^{274}$ Lai Si Tsui-Auch and Toru Yoshikawa, 'Institutional Change Versus Resilience: A Study of Incorporation of Independent Directors In Singapore Banks' (2015) 14 Asian Business and Management 91; Milhaupt (2003) on Japan.

275 Jennifer G Hill, 'Regulatory Responses to Global Corporate Scandals' (2005) 23 Wisconsin International Law Journal 367.

${ }^{276}$ Adrian Cadbury, Financial Aspects of Corporate Governance (1992) giving rise to the first UK Corporate Governance Code.

277 The evolution of UK corporate governance norms is discussed in Iris H-Y Chiu, 'Learning from the UK in the Proposed Shareholders' Rights Directive 2014? European Corporate Governance Regulation from a UK Perspective' (2015) 114 ZVgIRWiss 1.
} 
better manage and control risks. ${ }^{278}$ As these corporate scandals were attributed to fraudulent management, ${ }^{279}$ shareholder-centric ideology was not fundamentally disturbed.

It was not until the global financial crisis in 2007-9, where both management and shareholders in several failed financial institutions in the US, UK and Europe were criticised for having indulged in and condoned excessive risk taking, ${ }^{280}$ that some space was wedged for stakeholder or communitarian discourse to influence corporate law reform. First, regulatory intervention into corporate governance at banks and financial institutions ${ }^{281}$ and the institution of regulatory accountability ${ }^{282}$ introduced a public interest discourse into corporate governance, but not generally. ${ }^{283}$ Second, although the corporate and institutional sector continued to remain powerful in influencing corporate law reform and change, institutional shareholders, who were made more powerful in being able to engage informally in monitoring corporations, ${ }^{284}$ became increasingly subject to regulatory scrutiny in doing so. ${ }^{285}$ Finally, one of s $^{286}$ has argued that the upheaval and loss of social confidence in the wake of the crisis was monumental enough to culminate in the legalisation of certain corporate social responsibility aspects, ${ }^{287}$ the discourse of which had been earlier confined to soft law. ${ }^{288}$

There are increasing social pressures for corporations moving forward, such as to manage sustainability risks and address social issues, ${ }^{289}$ as corporations are seen as central, not peripheral, to

278 Sarbanes-Oxley Act 2002, see John C. Coffee, Jr., 'What Caused Enron? A Capsule Social and Economic History of the 1990s' (2004) 89 Cornell L. Rev. 269, 308-09 (2004); Geoffrey P. Miller, 'Catastrophic Financial Failures: Enron and More' (2004) 89 Cornell L. Rev. 423.

${ }^{279}$ Michael D Goldman and Eileen M Filliben, 'Corporate Governance: Current Trends and Likely Developments for the Twenty-First Century' (2000) 25 Delaware Journal of Corporate Law 683.

280 David Walker, A Review of Corporate Governance in Banks and Financial Institutions (Nov 2009).

${ }^{281}$ Regulatory interventions have been made to prescribe corporate governance and internal control organisation at financial institutions in order to overhaul their risk and control cultures. Basel Committee, Guidelines: Corporate Governance Principles for Banks (July 2015); European Banking Authority, Guidelines on Internal Governance under Directive 2013/36/EU (26 Sep 2017), discussion in Iris H-Y Chiu, Regulating (from) the Inside: The Legal Framework for Internal Control at Banks and Financial Institutions (Oxford: Hart 2015) and citations in chapters 2, 3, 4, 5 and 6.

282 House of Commons and House of Lords, Parliamentary Commission on Banking Standards, Changing Banking for Good (2013). This precedes the UK's introduction of the senior managers' regime, which is a regime for personal responsibility in banking misconduct, Iris $\mathrm{H}-\mathrm{Y}$ Chiu, 'Regulatory Duties for Directors in the Financial Services Sector and Directors' Duties in Company Law- Bifurcation and Interfaces' (2016) Journal of Business Law 465.

283 Peter O Mülbert, 'Corporate Governance of Banks after the Financial Crisis - Theory, Evidence, Reforms' (April 2010) ECGI Law Working Paper No 130/2009 http://ssrn.com/abstract=1448118.

${ }^{284}$ Via Stewardship Codes, the pioneering one introduced in the UK in 2010.

285 The EU Shareholders' Rights Directive 2017 at Arts 3g-I; Iris H-Y Chiu, 'European Shareholder Rights Directive Proposals: A Critical Analysis in Mapping with the UK Stewardship Code?' (2016) 17 ERA Forum 31, the UK's revised Stewardship Code 2020 which sets best practices for asset owners and managers in their investment management.

${ }^{286}$ Chiu, 'Institutional Theory' (2018).

287 Such as disclosure regulation, supply-chain focused obligations, anti-corruption and anti-tax avoidance regulations that intervene into corporate processes, see ibid and cites within.

${ }^{288}$ Section B, and Harri Kalimo; Tim Staal, 'Softness in International Instruments - the Case of Transnational Corporations' (2014) 41 Syracuse J. Int'I L. \& Com. 257; Fabrizio Cafaggi, 'New Foundations of Transnational Private Regulation'(2011) 38 Journal of Law and Society 20; Colin Scott, Fabrizio Cafaggi \& Linda Senden, 'The Conceptual and Constitutional Challenge of Transnational

Private Regulation' (2011) 38 J. of L. \& Soc. 1.

289 Business and human rights was an earlier starting point, see UN Guiding Principles for Business and Human Rights (2011); Larry Catá Backer, 'The Guiding Principles of Business and Human Rights at a Crossroads: The 
global public concerns and goods. The technological revolutions in AI and DLT facilitate more diffused and flatter information structures that can empower more stakeholders and citizens. Hence, existing power structures, such as the managerial and shareholder classes, are demonstrating posturation towards internalising these challenges, in order to continue shaping institutional change and defending extant power structures. The powerful managerial class in the US, represented by the Business Roundtable, has reshaped director primacy rhetoric in line with the stewardship of sustainability and social responsibility goals. ${ }^{290}$ Many other policy-makers such as the EU and UK continue to adopt the shareholder primacy ideology by endowing shareholders' theoretical monitoring role with greater levels of such public interest, such as by enhancing institutional shareholders' accountability. The EU Shareholders' Rights Directive 2017 compels institutions to consider 'environmental, social and governance' risks in their portfolios and their monitoring of asset managers. ${ }^{291}$ Further reforms to explicitly require disclosure by institutions in relation to managing sustainability risks are afoot. ${ }^{292}$

The above account of institutional change in corporate law is reflected in many jurisdictions. We turn now to derive a combined theoretical framework for how technological change may affect corporate law and governance reform.

\section{A Combined Multi-Theoretic Framework for Institutional Change in Corporate Law/Governance in Response to Technology Change}

We introduce a visual representation of the combined theoretical framework for how technology revolutions in Al and DLT would shape institutions in corporate law and governance. Theories of technology and institutional change suggest that institutional change culminates at the end process of social mobilisation and legitimation of the 'new ideology' associated with new technology. We suggest that in the corporate law and governance context, as there is a perennial battlefield of ideological contest between powerful groups in the political economy and the occasionally-heard stakeholders, technology change would be reframed in contesting ideology preferred by the tussling groups in order to make bids for institutional change. In sum, we suggest that the major power groups influencing corporate law and governance norms would mobilise old ideology with technological spins in order to achieve incremental institutional changes aligned with their incentives and interests. We suggest it would be unlikely that institutional change would be achieved to facilitate radical/disruptive or fundamental/structural changes discussed in Section $\mathrm{A}$ to the extent that it denudes extant power structures of their power.

State, the Enterprise, and the Spectre of a Treaty to Bind Them All' (2014) at http://ssrn.com/abstract=2462844; Karin Buhmann, 'Public Regulators and CSR: The 'Social Licence to Operate' in Recent United Nations Instruments on Business and Human Rights and the Juridification of CSR' (2016, Journal of Business Ethics) at http://ssrn.com/abstract=2705360. There is increasing focus on corporate internalisation of sustainability goals such as the new EU proposal for climate risk reporting, see summary at 'Financial Groups at the Front of Fight against Climate Change' (Financial Times 9 Sep 2019) at https://www.ft.com/content/ed036756-854f-3668-a9a9-6d00881cf13d.

290 'Business must act on a new corporate purpose' (Financial Times, 19 Aug 2019) at https://www.ft.com/content/3732eb04-c28a-11e9-a8e9-296ca66511c9.

${ }^{291}$ Articles $3 g$ and $3 \mathrm{~h}$.

292 EU High Level Expert Group on Sustainable Finance (HLEG), Financing a Sustainable European Economy (2018) and proposed in Commission Proposed Regulation on disclosures relating to sustainable investments and sustainability risks and amending Directive (EU) 2016/2341, Art 3. 


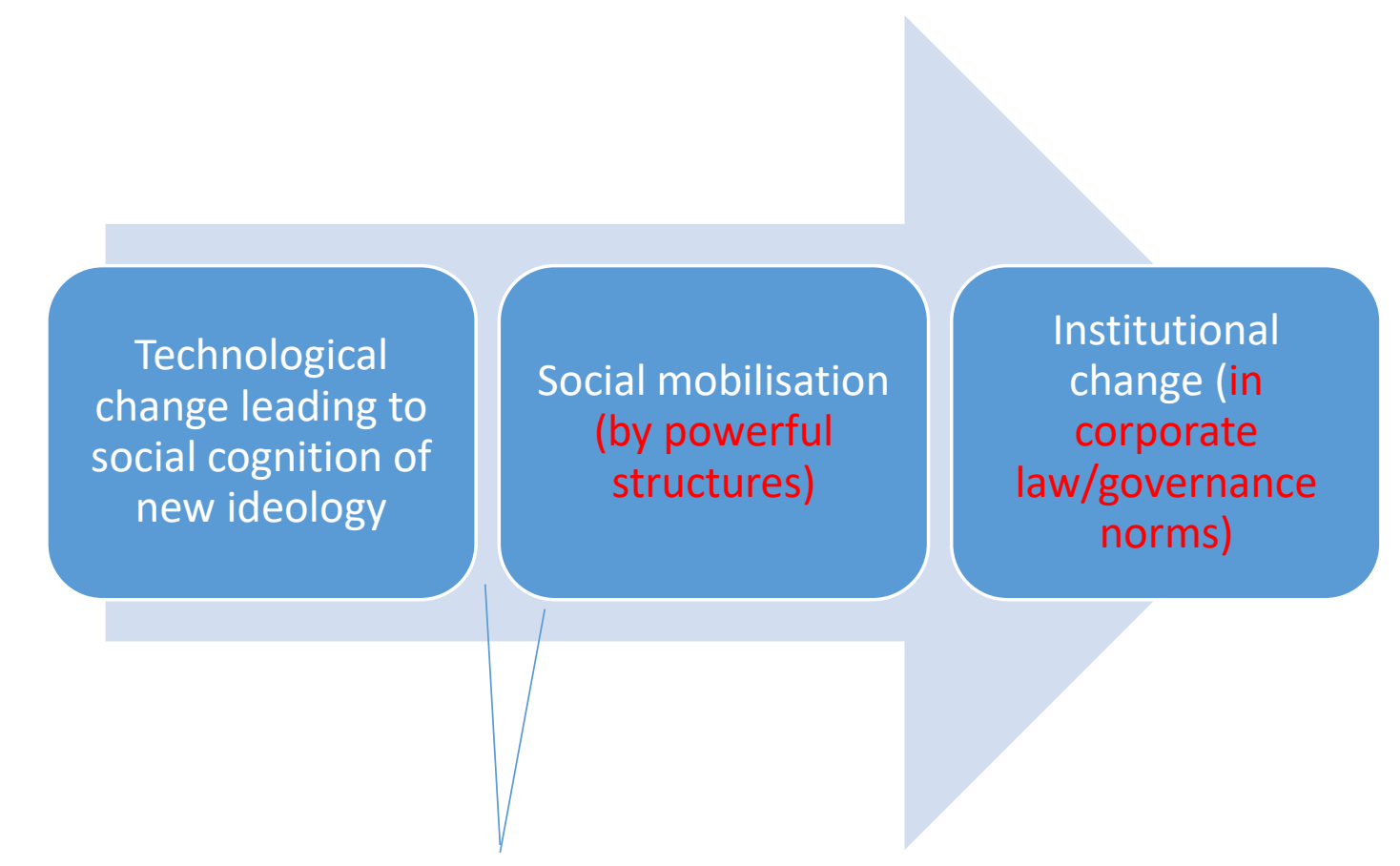

Reframing of old ideology in

corporate law

Figure 1: Diagram representing the theoretical framework for technological change and its relationship to institutional change in corporate law and governance norms

We turn now to Section $\mathrm{C}$ which applies the multi-theoretical framework above and discusses three concrete predictions we make about the future of corporate law and governance norms.

\section{Technology vs Ideology- Predicting the Verdict in Corporate Law and Governance Norms}

In this Section, we predict that extant powerful structures would be reinforced by technological revolutions and not made obsolete. Threats perceived by powerful structures in relation to Al would be mitigated by increased calls for ethical regulation. The threats perceived by powerful structures in relation to DLT would be mitigated by absorption and reframing of DLT for corporate use.

\section{The Hold of the Powerful Political Economy Groups on Ideology and Institutional Change}

In Section A, we depicted the possible radical/disruptive or fundamental/structural changes that could shake up corporate organisation and governance, such as Al-only corporate personalities without shareholders and directors or DLT-enabled platform governance that supplants corporate governance. These require ideological challenges to corporate law and governance as director primacy may become redundant while communitarian forms of governance would be in ideological contest with capital-controlled Al-fronted businesses. We suggest that ideological challenges will be mediated by existing powerful structures in the corporate economy. In this manner, Al and DLT will primarily be framed in incentive-based or efficiency driven terms to reinforce existing power structures even if they may change some ways 'things are done'. However, radical/disruptive or fundamental/structural changes that threaten those power structures would unlikely be mobilised.

The managerial and shareholding class are both likely to welcome Al and DLT in terms of improving efficiency and delivering the corporate purpose and profits. We are unlikely to see much opposition to DLT, making it quicker and more efficient to organise trade finance or supply chains. We will also 
see Al being deployed to reform information-based tasks, from risk management ${ }^{293}$ to corporate reporting. ${ }^{294} \mathrm{Al}$ would also likely be used in evaluative tasks and the Board may not even shy from Board evaluation using Al. ${ }^{295}$ However, the Board and C-suite officers would likely insist on the ultimate delivery of a human (usually value) judgment, even if assisted to a great extent by Al, where liability or legal risks may be implicated. This is because while directors and managers may be exposed to legal risk or liability, these risks are substantially mitigated by legal mechanisms (including but not limited to the business judgment rule and $\mathrm{D}+\mathrm{O}$ insurance). In other words, management would likely increase rhetoric in relation to supporting and upholding existing legal duties and institutions while appearing to be progressive in relation to technological responsiveness.

As Möslein points out, ${ }^{296}$ there would be intractable problems judging robots ex post in care and skill regimes, and in programming robots ex ante to adhere to such regimes. The directors' duty of care and skill is an open-ended and heavily human-centred regime for judgment, based on the standard of care expected of a reasonable director of the equivalent skills and qualifications. ${ }^{297}$ Humancentredness is also key to the loyalty regime. ${ }^{298}$ It may be argued that directors may be incentivised to support their replacement as the obsolescence of human management, as suggested by Petrin, ${ }^{299}$ results in liability being imposed on software providers. However, we are of the view that directors are unlikely to be deterred by liability regimes as the incentives presented by power, pay and perks for being in the managerial class are more attractive. ${ }^{300}$ There are also other vested interests in supporting the essential human-ness of the managerial class, such as lucrative business schools that educate and train the managerial elite.

There is another reason why Al will not replace the human-centeredness of the directors' liability regime. Because Al is designed by humans for humans, Al is likely to mirror and entrench the views of humans. ${ }^{301}$ As such, it seems implausible, at least for now, that directors or managers can escape liability totally, contrary to the suggestions by certain commentators. Management can seek to use Al to its advantage in two ways. First, management can influence the coding process, so as to generate certain predictive analytics in a way that will advance its own interests. ${ }^{302}$ After all, the coder or supplier of the Al will be sensitive to the wishes of those purchasing their software. This conflict of interest is similar to that of a company engaging proxy advisors for services. ${ }^{303}$ Second, insofar as the Al software periodically requires updated data to be fed into it, management can

\footnotetext{
${ }^{293}$ Gary L Evans, 'Disruptive Technology and the Board: The Tip of the Iceberg' (2017) 3 Economics and Business Review 205. Ernst and Young, 'When Boards Look at Al- What Do They See?' at https://www.ey.com/en_gl/board-matters.

${ }^{294}$ Financial Reporting Council, Al and Corporate Reporting (2019) at https://www.frc.org.uk/getattachment/e213b335-927b-4750-90db-64139aee44f2/Al-and-CorporateReporting-Jan.pdf.

${ }^{295}$ Ernst \& Young (above); 'Artificial Intelligence and the Impact on the Company Secretary' (CSSA, Sep 2018). 296 (2018).

297 S174, UK Companies Act 2006, Re Brian D Pierson (Contractors) Ltd [1999] BCC 26.

${ }^{298}$ Such as whether a director who resigns may be able to use existing knowledge and expertise to help set up a future competing business, e.g. Foster Bryant Surveying Ltd v Bryant [2007] EWCA Civ 200.

299 Petrin (2019).

300 The growth of executive remuneration in the corporate sector has been marked especially in Western jurisdictions, 'CEO Compensation in the US v the World' at https://work.chron.com/ceo-compensation-vsworld-15509.html.

${ }^{301}$ Enriques and Zetsche (2019); Dignam (2019).

302 Enriques and Zetzsche (2019).

303 Tao Li, "Outsourcing Corporate Governance: Conflicts of Interest Within the Proxy Advisory Industry" (2018) 64 Management Science 2473; Matthew Fagan, "Third-Party Institutional Proxy Advisors: Conflicts of Interest and Roads to Reform" (2018) 51 University of Michigan Journal of Law Reform 621.
} 
selectively feed certain data and omit others. Thus, even if the notion of Al directors becomes a reality, it can never completely eliminate directorial or managerial liability insofar as human agents are responsible for the selection, purchase, maintenance and operation of the Al machine.

We also believe that the irreplaceability of the essentially human directorial organ of the company will be supported by shareholders, even where there is separation of ownership from control. There is an argument to be made that Al directorial organs may make more informed and consistent decisions than the fallible human, ${ }^{304}$ but there is also countervailing expert evidence that supports human supremacy in deciding on qualitative or strategic matters due to the complexity of the human instinct and the visionary nature of forward-looking judgment. ${ }^{305}$ There is unlikely to be conclusive 'science' that says Al are superior directorial organs than humans. ${ }^{306}$ Indeed, although narrow Al can engage successfully in predictive analytics, namely statistical analysis and the identification of patterns of decision-making, ${ }^{307}$ there is no evidence that $\mathrm{Al}$ is equipped to handle complex, strategic decision-making that entails the weighing of competing facts and evidence; nor has it been demonstrated that Al can understand the complex trade-offs that are required in board decisions.

The replaceability of the Board, if at all viable and appropriate, is a choice for shareholders. We argue that shareholders prefer the existing regime, where they can call on directors to account and also engage in compensatory litigation in securities or derivative suits where directors have been negligent. The obsolescence of the directorial organ would mean structural changes to the shareholder litigation landscape. ${ }^{308}$ Given the uncertainties of calling product providers of software to account, ${ }^{309}$ shareholders will face uncertainty and significant disruption to a familiar landscape of risk and compensatory allocation.

However, what will change is that the managerial class cannot avoid pressures from shareholders, competitors and the market to demonstrate optimal deployment of new technologies. ${ }^{310}$ Hence, $\mathrm{Al}$ may be used to assist in strategy, such as the role of VITAL discussed in Section A, or assist company secretaries. However, as the company secretary's advisory role is an essential aspect of directors' discharge of their duty of care and skill, it is unlikely that such a role will be fully automated. ${ }^{311}$ In turn, the managerial class will demonstrate human supremacy over Al by changing risk, governance and Board structures to manage and govern $\mathrm{Al}$ in its use and deployment in the corporation. Boards would push for, and shareholders would welcome, ${ }^{312}$ the establishment of innovation committees or technological oversight committees on Boards ${ }^{313}$ as well as a governance structure at the highest

\footnotetext{
${ }^{304}$ Enriques and Zetzsche (2019).

305 Jarrahi (2018).

306 The inconclusive arguments are covered in Enriques and Zetzsche (2019) and Petrin (2019).

307 Harry Surden, “Machine Learning and Law" (2014) 89 Washington Law Review 8.

${ }^{308}$ See Dan W Puchniak and Masafumi Nakahigashi, 'Japan's Love for Derivative Actions: Irrational Behavior and Non-Economic Motives as Rational Explanations for Shareholder Litigation' (2012) 45 Vanderbilt Journal of Transnational Law 1 on an incentive-based discourse for shareholder litigation in the US and Japan.

${ }^{309}$ Section A.

310 Irving Low, 'Is Technology Disrupting Governance?' (Business Times Singapore, 20 Sep 2018).

311 'Artificial Intelligence and the Impact on the Company Secretary' (CSSA, Sep 2018).

312 Ronald F Premuroso and Som Bhattacharya, 'Is There a Relationship between Firm Performance, Corporate Governance, and a Firm's Decision to Form a Technology Committee?' (2007) 15 Corporate Governance: An International Review 1260.

${ }^{313}$ Moksh Matta, Hassan Cavusoglu and Izak Benbasat, 'Understanding the Board's Involvement in Information Technology Governance' (2016) at http://ssrn.com/abstract=2778811; Lawrence J Trautman and Kara Altenbaumer-Price, 'The Board's Responsibility for Information Technology Governance' (2011) 28 The John Marshall Journal of Computer and Information Technology Law 313.
} 
level for overseeing technological revolutions. These measures would likely be seen as being modernist and responsive but the most radical or fundamental changes to power would likely be stealthily sidelined. The managerial class is also likely to add its weight to championing for greater scrutiny, regulation and ethicisation of Al.

What about the radical, almost fundamental/structural change that DLT offers, which is real-time accountability, information-sharing with shareholders, facilitation of their decision-making, ${ }^{314}$ perhaps rendering the Board or management obsolete? This is unlikely, from both a technical and an ownership structure perspective.

From a technical lens, any deployment of DLT in corporate governance is likely to be permissioned and not permissionless. The difference between permissionless and permissioned DLT ${ }^{315}$ is that the former allows anyone to join the peer-to-peer network ${ }^{316}$ but the latter restricts access to only identified participants based on a set of rules. ${ }^{317}$ As the Board has a duty to maintain proper internal controls and a risk management system, DLT for corporate governance cannot be permissionless. Hence the rules and governance structure of the DLT would have to be decided by human decisionmakers in the organs of the company. DLT may transform the platform of interactions at best but would not itself render the usual corporate governance actors obsolete.

From an ownership structure perspective, in concentrated ownership structures where the managerial and shareholder class are often fused or interrelated, there would be no need to mobilise new ideology for shareholder decision-making powered by the DLT. Given that controlling shareholders are the norm for the majority of the world's companies, ${ }^{318}$ DLT will only play a limited role in enhancing accountability by controlling shareholders and in facilitating the exercise of shareholder governance rights by non-controlling shareholders. After all, controlling shareholders will hold positions in the board and management (as in family owned companies) or control appointments to the board (as in SOEs). In other words, even if DLT increases the speed of voting and the accuracy of vote tabulation, and hence incentivises minority shareholders to exercise their voting rights and exert influence, the controlling shareholders will not be outvoted and will continue to retain power. Thus, this institutional change would be relevant only to dispersed ownership structures. Section A has discussed incremental market adoption and legal changes in several jurisdictions to facilitate DLT-powered shareholder meetings. However, this is far from changing entrenched institutions such as the annual general meeting and the powers of shareholder intermediaries. ${ }^{319}$

Would DLT revolutionise corporate decision-making by making it possible for shareholders to participate in real-time alongside directors? The managerial class would have no incentive to seek more and frequent general meetings and even real-time decision making. This is partly because such a change would erode the power and importance of the managerial class, although the directorial organ can be shielded by such general meeting decision-making when it comes to liability. The

\footnotetext{
${ }^{314}$ Section A and citations.

${ }^{315}$ Anna Donovan, '(Shadow) Banking on the Blockchain: Permissioned Ledgers, Interoperability and Common Standards' in Iris H-Y Chiu and lain G MacNeil (eds), Research Handbook on Shadow Banking (Cheltenham: Edward Elgar 2018) at ch11.

${ }^{316}$ Xiwei Xu et al., "A Taxonomy of Blockchain-Based Systems for Architecture Design” 2017 IEEE International Conference on Software Architecture (ICSA), Gothenburg 2017, 243.

317 Yermack (2017).

318 OECD Corporate Governance Factbook 2019 at 12.

319 The custodians and investment funds holding securities interests on behalf of ultimate investing beneficiaries.
} 
managerial class would likely deploy the rhetoric of inefficient 'governance by referenda' to resist any move to real-time decision-making by shareholders.

Shareholders are as unlikely to seek structural changes to the annual general meeting. Shareholder involvement overcomes the agency problem, and by marginalising the directorial organ, corporations would save on expenses in relation to executive remuneration, leaving more room for dividends. However, institutional shareholders are still likely to prefer a back seat. They welcome having a monitoring role and the legal regimes that enhance their powers to monitor and challenge, but are likely uninterested in taking over the full suite of management themselves. This is because institutions generate their investment returns by both market gains (trading) and productive gains (investing in equities and obtaining dividends from real profitability). As market trading has become increasingly important to investment management ${ }^{320}$ and shareholder engagement is costly in terms of time and effort, it is already difficult to persuade institutions to undertake the latter. ${ }^{321}$ Importantly, in the US, index funds, which account for $25 \%$ of shares in all S\&P companies, the percentage of which is projected to increase to $40 \%$ in the next twenty years, have been found to engage in few stewardship activities and defer excessively to corporate managers. ${ }^{322}$ DLT is unlikely to bring about a significant change in the incentives and strategies of index funds whose business model is to minimise cost.

Further, institutions would likely have to incur more advisory expenses, such as the appointment of proxy advisory firms to engage in expanded corporate governance roles, making cost a deterring factor. Such a change may appeal to activist hedge funds ${ }^{323}$ whose investment management strategy is to get involved in management in order to shape value creation by the company. This means that by increasing the intensity of shareholder powers and involvement in corporate decision-making, the market for corporate influence would sharply be captured by activist hedge funds. This implication may not be welcomed by all shareholders. ${ }^{324}$ It may also be argued that DLT will not have the effect of incentivising activism by hedge funds because DLT provides a high level of transparency that is adverse to hedge fund strategies. ${ }^{325} \mathrm{~A}$ central strategy of activist hedge funds is to surreptitiously buy shares in the company until it reaches a certain level that triggers legally required disclosure. ${ }^{326}$

\footnotetext{
${ }^{320}$ Barker and Chiu (2017) at ch2.

${ }^{321}$ One of the rationales underlying the UK Stewardship Code 2010, discussed in Department for Business, Innovation and Skills, The Kay Review of UK Equity Markets and Long-Term Decision Making (Final Report, July 2012).

322 Lucian A Bebchuk and Scott Hirst, "Index Funds and the Future of Corporate Governance: Theory, Evidence, and Policy" (2019) 119 Columbia Law Review (forthcoming).

${ }^{323}$ Brian Cheffins and John Armour, 'The Past, Present and Future of Shareholder Activism by Hedge Funds' (2012) Journal of Corporation Law also at http://papers.ssrn.com/sol3/papers.cfm?abstract id=1932805. ${ }^{324}$ Some shareholders follow hedge fund activists in order to benefit from their efforts and the consequent boost to companies' share price, see Marco Becht, Julian Franks, Jeremy Grant and Hannes Wagner, 'The Returns to Hedge FundActivism: An International Study' (2014) at http://ssrn.com/abstract=2376271; Lucian Bebchuk, Alon Brav and Wei Jiang, 'The Long-Term Effects of Hedge Fund Activism' (2015) 115 Columbia Law Review 2085; but hedge fund activism has also been reported to create destructive effects, John C Coffee and Darius Palia, 'The Impact of Hedge Fund Activism: Evidence and Implications' (2014) at http://ssrn.com/abstract=2496518; Marcel Kahan and Edward B Rock, 'Hedge Funds in Corporate Governance and Corporate Control' (2007) 155 University of Pennsylvania Law Review 1021; Frank Partnoy, 'U.S. Hedge Fund Activism' (2015) at http://ssrn.com/abstract= 2585290.

325 Yermack (2017).

${ }^{326}$ Lucian Bebchuk and Robert Jackson Jr, "The Law and Economics of Blockholder Disclosure" (2012) Harvard Business Law Review 39.
} 
Finally, if there were to be changes in the aspect of shareholder power, such as enhanced decisionmaking facilitated by real-time information reporting, then the corresponding question of corporate law changes to shareholders' duties would arise. ${ }^{327}$ Shareholders now enjoy the freedom to exercise their vote as they please, ${ }^{328}$ and many institutions would not relish the conflict between their duties in investment management to their beneficiaries, and duties to the companies that they are invested in. In sum, there would unlikely be sufficient consensus in the institutional shareholders' universe to mobilise such an institutional change.

In the same vein, it is unlikely that ideological change towards disintermediating the investment chain ${ }^{329}$ powered by DLT would be mobilised. The investment intermediaries, who are the powerful shareholder class, would unlikely support such ideological change as investment funds have no legal obligation to empower their beneficiaries to vote directly anyway. ${ }^{330}$ Further, if particular governance rights are allocated to beneficiaries, does this mean that their investment risk becomes tied to particular securities investments? Would this have the implication of depriving investors of the benefit of diversified risk allocation in a collective fund vehicle, therefore being counterproductive to their investment objectives? Although investment intermediaries have come under criticism for not being effective shareholders in stewarding their beneficiaries' assets, ${ }^{331}$ such criticism cannot be legally conclusive with regard to their discharge of fiduciary duties to their beneficiaries. ${ }^{332}$ Further, the policy makers' approach is to clarify and enhance the investment intermediary's fiduciary duty rather than to directly empower beneficiaries. ${ }^{333}$ It can also be argued that the beneficiary group has mixed interests in being directly empowered. Some beneficiaries enjoy the lack of transparency as to their identity, ${ }^{334}$ while many individual savers in funds would likely experience inertia or the collective action problem to participate directly in corporate governance.

The powerful managerial and shareholder groups will frame technological change within an incentive-based paradigm in order to mobilise ideologies that are unlikely to result in radical or fundamental/structural change to corporate law and governance that erodes their powers. There may however be incremental change, such as the new law in Delaware that permits DLT to be used for communications with shareholders. ${ }^{335}$ It may be queried whether bottom-up forces may challenge the shareholder and managerial groups in their grip on and framing of technological change, so as to favour futuristic visions of managerial replacement, shareholder governance or indeed, stakeholder participation. For instance, stakeholder groups may argue that managerial replacement is optimal as Al would be objective, consistent and perhaps less susceptible to

\footnotetext{
327 Discussed in Iman Anabtawi and Lynn Stout, “Fiduciary Duties for Activist Shareholders" (2008) 60 Stanford Law Rev 1255.

${ }^{328}$ Northern Counties Securities Ltd v Jackson \& Steeple Ltd [1974] 2 All ER 625.

${ }^{329}$ Van der Elst and LaFarre (2017).

${ }^{330}$ Discussed in Section A.

${ }^{331}$ Simon CY Wong, 'Is Institutional Investor Stewardship Still Elusive?' (2015) Butterworths Journal of Banking and Financial Law 508; Arad Reisberg, 'The UK Stewardship Code: On a road to Nowhere' (2015) 15 The Journal of Corporate Law Studies 217.

332 The Law Commission, Fiduciary Duties of Investment Intermediaries (1 July 2014) contains a useful summary of the primarily financially-driven nature of the fiduciary duty. As funds use a variety of strategies including their corporate governance roles in seeking financial performance, such roles are not exclusively determinative of the discharge of fiduciary duties.

${ }^{333}$ Such as the European Commission's thinking to make sustainability considerations part of the fiduciary duty of funds towards their beneficiaries, HLEG (2018).

334 Geis (2018), Nord (2019).

335 Laster and Rosner (2018).
} 
sociopathic tendencies that have been written about many corporate leaders in power. ${ }^{336}$ This is a different perspective than just the agency problem, and the weeding out of sociopathic corporate leaders can be perceived to be socially beneficial. Stakeholder groups may also press for more involvement in corporate governance as the enabling features of the DLT can accommodate distributed participation, making obsolete traditional arguments about the inefficacies of having too many groups represented at the corporate governance table. ${ }^{337}$

However, bottom-up forces have had an uphill climb in influencing corporate law and regulation, ${ }^{338}$ and in the area of corporate social responsibility in which they have been the most influential, soft law features much more than legalisation. ${ }^{339}$ The breakthrough of bottom-up forces in shaping ideological and institutional change in corporate law and governance has been sporadic and modest overall.

Next, although Al and DLT will be institutionally mediated within corporate law and governance, the corporate sector would have to reckon with broader movements in the social context. We observe that general social mobilisation, not just by the managerial class, is taking place for the ethical and regulatory governance of Al. Such frameworks will firmly confine Al to an anthropocentric paradigm of governance. This general movement will resonate with the actors in the landscape for corporate law and governance reform.

\section{Ethical and Regulatory Governance of Al}

The general tide of social change in the face of technological change would likely converge on the cautious and incremental, especially in the West. This is because AI and DLT are likely to unleash social dialogics that countervail each other. Even if DLT offers new ways of thinking about economic agency in freer terms, such as not being tied down to a day job in a corporatized institution, the insecurities and income volatility as well as potential exploitation in the gig economy have been wellcanvassed. ${ }^{340}$ Fundamental questions are likely to be socially navigated not only on the basis of incentives, but also in relation to more normative and collective reflection on the meaning of life and community. ${ }^{341}$ These dialectics are likely to be protracted.

Further, temporal conditions in the West have changed from relative economic stability, from the 1980 s to early 2000s, to increasing likelihood of turbulence, especially in relation to political conditions. The rise of far right nationalism as well as anti-establishment/anarcho-capitalism are both observed, ${ }^{342}$ and under such temporal conditions, it has been opined ${ }^{343}$ that general

\footnotetext{
336 Jerome Want, Corporate Cultures (NY: St Martin's Press, 2006).

337 John Argenti, “Stakeholders: The Case Against" (1997) 30(3) Long Range Planning 442.

${ }^{338}$ Chiu, 'An Institutional Theory' (2018).

339 Ibid.

${ }^{340}$ Brishen Rogers, 'Employment Rights in the Platform Economy: Getting Back to Basics' (2016) 10 Harvard Law and Policy Review 480; Alberto Di Minin, Lenny Mendonca, Erkki Ormala and Peter Evans, 'Assessing the Platform Economy' (2016) 32 Issues in Science and Technology 13.

${ }^{341}$ Remington Tonar, 'Humanity's Search for Meaning in the Age of Al and Automation' (4 Sep 2018) at https://medium.com/@Altheist/humanitys-search-for-meaning-in-the-age-of-ai-and-automation-

$18 \mathrm{c} 850544502$. Living with robots would raise questions regarding the rightfulness of anthropocentric notions of agency and morality, which need to be rethought for individuals and society in a context of such side-byside living, David J Gunkel, The Machine Question: Critical Perspectives on Al, Robots and Ethics (Mass: MIT Press 2012).

${ }^{342}$ Such as the Brexit referendum in the same year in the UK, turbulent political conditions in some European countries such as Italy and Greece and far-right governments in Austria and Hungary have raised concerns. 343 Iyigun and Rubin (2017).
} 
conservatism regarding technology-led institutional change may prevail. Even if there is still a high and healthy pro-innovation stance supported by authorities and markets in the US and UK, ${ }^{344}$ there is less likelihood of a 'bubbly' embrace of technological change and the implications of institutional change.

There is a different institutional context in China in terms of social remodelling using Al and DLT, such as social 'scoring' of citizens ${ }^{345}$ and the deployment of facial recognition technologies. ${ }^{346}$ The top-down enforcement of technological management as a new administrative state or even rule of law $^{347}$ creates institutional change even though the social mediation of such change may yield unpredictable results. ${ }^{348}$ In the West, such technological management by authorities remains at an experimental stage ${ }^{349}$ and this can be attributed to the institutional framework at work where different aspects of social mediation are already taking place, introducing dialogic forces that countervail and balance each other.

This underlying social context would reinforce the incrementalism likely to be experienced in corporate law and governance norms. We predict that there may be convergence from many social quarters on subjecting Al and DLT to social scrutiny and governance. Hence, we already see a rise in voluntary ethical governance of Al by the technological sector, such as the standards introduced by the IEEE, the professional organisation for the technology sector, ${ }^{350}$ and the 'Partnership on Al to Benefit People and Society', an alliance formed by Google, Amazon, IBM, Facebook and Microsoft, to explore research and engage in stakeholder partnership to develop standards for the Al industry. ${ }^{351}$

However, leaving ethical governance to the technological sector is widely criticised to be insufficient as technologists often view ethical issues as 'ex post' problems to be fixed with a technological

${ }^{344}$ Such as the Innovate UK initiative, https://www.gov.uk/government/organisations/innovate-uk; see Department of Business, Government Response to House of Lords Artificial Intelligence Select Committee's Report on Al in the UK: Ready, Willing and Able? (June 2018) at https://www.parliament.uk/documents/lordscommittees/Artificial-Intelligence/Al-Government-Response2.pdf where it is set out that exploring the capabilities and efficiencies of $\mathrm{Al}$ and a data economy are priorities but these require trust and ethical governance. The EU also embraces the innovative potential of Al but with caution to 'leaving no-one behind' in socio-economic changes and in setting up ethical and legal frameworks, Communication from the Commission to the European Parliament, the European Council, the Council, the European

Economic and Social Committee and the Committee of the Regions, Artificial Intelligence for Europe (25 April 2018) at https://ec.europa.eu/digital-single-market/en/news/communication-artificial-intelligence-europe.

345 'China Ranks Citizens with a Social Credit System: Here's What You Can Do Wrong and How You Can be

Punished' (The Independent, 10 April 2018) at https://www.independent.co.uk/life-style/gadgets-andtech/china-social-credit-system-punishments-rewards-explained-a8297486.html.

346 'China: Facial Recognition and State Control' (The Economist, 24 Oct 2018) at

https://www.youtube.com/watch?v=|H2gMNrUuEY.

${ }^{347}$ Brownsword (2019).

$348 \mathrm{Li}$ and Reimers (2012).

349 'How London became a test case for using facial recognition in democracies' (Financial Times, 1 August 2019) showing how the trialling of such a system generated debate and controversy, at

https://www.ft.com/content/f4779de6-b1e0-11e9-bec9-fdcab53d6959 and the London mayor expressed concern at such use of technology in private developments of public places such as Kings Cross station, see 'London Mayor Writes to Kings Cross Owner over Facial Recognition' (The Guardian, 14 Aug 2019) at https://www.theguardian.com/technology/2019/aug/13/london-mayor-writes-to-kings-cross-owner-overfacial-recognition-concerns.

350 IEEE Global Initiative for Ethical Considerations in Artificial Intelligence (AI) and Autonomous Systems (AS), at https://standards.ieee.org/news/2017/ieee p7004.html with a list of Standards.

351 'Partnership on Al' formed by Google, Facebook, Amazon, IBM and Microsoft' (The Guardian, 28 Sep 2016) at https://www.theguardian.com/technology/2016/sep/28/google-facebook-amazon-ibm-microsoftpartnership-on-ai-tech-firms. 
solution, ${ }^{352}$ instead of as a normative learning paradigm that can shape software engineers' mindsets. ${ }^{353}$ The bridge between technologists' approach and social engagement is still under construction. Technologists see the embedment of ethics as the need to code specific choice sets and preferences, ${ }^{354}$ but research highlights a lack of engagement between the technological sector and ethicists. ${ }^{355}$ Technologists are possibly far from understanding the debates and dilemmas that ethicists face, ${ }^{356}$ such as answering the question of ' what is obscene?'357 or who should make ethical choices. $^{358}$

The OECD ${ }^{359}$ has introduced broad principles for Al development, namely:

(a) Respect for human autonomy;

(b) Prevention of harm;

(c) Fairness; and

(d) Explicability.

More work needs to be done with these principles, regarded by many as only a starting point, as their high level nature needs to be translated into application for technology designers. ${ }^{360}$ Also, the scope of ethical Al principles can be further expanded by taking into account other values such as universal human rights and sustainability in the future. ${ }^{361}$ It also remains uncertain how these principles can provide robust governance in the absence of mandatory accountability ${ }^{362}$ or auditing of technological developments. Researchers are increasingly opening up the black box of machine learning to determine the 'explicability' of algorithmic decision-making and the aspects in which it

352 Thilo Hagendorf, 'The Ethics of Al Ethics' (2019) at https://arxiv.org/ftp/arxiv/papers/1903/1903.03425.pdf; Alan K Mackworth, 'Architectures and Ethics for Robots Constraint Satisfaction as a Unitary Design Framework' in Michael Anderson and Susan Leigh Anderson (eds), Machine Ethics (Cambridge: CUP 2011) at ch19.

353 Hagendorf (2019); Michael Veale, Reuben Binns and Jef Ausloos, 'When Data Protection by Design and Data Subject Rights Clash' (2018) 8 International Data Privacy Law 105.

354 James H Moor, 'The Nature, Importance, and Difficulty of Machine Ethics' in Anderson and Anderson (eds, 2011), ch1; Selmer Bringsjord, Joshua Taylor, Bram van Heuveln, Konstantine Arkoudas, Micah Clark and Ralph Wojtowicz, 'Piagetian Roboethics via Category Theory Moving beyond Mere Formal Operations to Engineer Robots Whose Decisions Are Guaranteed to be Ethically Correct' in Anderson and Anderson (eds, 2011), ch20; Luís Moniz Pereira and Ari Saptawijaya, 'Modelling Morality with Prospective Logic' in Anderson and Anderson (eds, 2011), ch22; Susan Leigh Anderson and Michael Anderson, 'Prima Facie Duty Approach to Machine Ethics: Machine Learning of Features of Ethical Dilemmas, Prima Facie Duties, and Decision Principles through a Dialogue with Ethicists' in Anderson and Anderson (eds, 2011), ch27. These chapters show that ethical capacity is built into a robot largely by coding choice sets, and machine engagement with ethics can never be the same as human engagement at a sentient level.

355 Hagendorf (2019); Veale et al (2018).

${ }^{356}$ Various ethical strands of thought are also in conflict with each other such as deontological and utilitarian perspectives, see J Storrs Hall, 'Ethics for Machines' in Anderson and Anderson (eds, 2011), ch3; James Gips, 'The Ethical Robot' in Anderson and Anderson (eds, 2011), ch14; Thomas M Powers, 'Prospects for a Kantian Machine' in Anderson and Anderson (eds, 2011), ch26.

${ }^{357}$ Amitai Etzioni and Oren Etzioni, 'Al-assisted Ethics' (2016) 18 Ethics and Information Technology 149.

${ }^{358}$ Should Al ethics be left to the individual to determine what is best for himself/herself- such as proposed by Etzioni and Etzioni (2016).

359 OECD Principles on Al at https://www.oecd.org/going-digital/ai/principles/.

${ }^{360}$ Brent Mittelstadt, 'Al Ethics: Too Principled to Fail?'(2019) at

https://papers.ssrn.com/sol3/papers.cfm?abstract_id=3391293.

361 Hagendorf (2019).

362 The scrutiny of algorithmic operations in finance driving trading decisions, for example, has been lagging and is sub-optimal because of the systemic impact of such operations, see Frank Pasquale, The Black Box Society (Mass: Harvard University Press 2015). 
should be made explicable, such as the type and failure modes of evidence the machine has relied upon. ${ }^{363}$

Social mobilisation in navigating technological changes may gradually converge upon a mixture of industry, stakeholder and regulatory initiatives for governing $\mathrm{Al}^{364}$ perhaps networked at an international level. ${ }^{365}$ Co-regulatory measures are likely to be fostered, as relying on any one group of constituents such as industry, stakeholders or regulators would unlikely generate a fully informational and strategic matrix for initiatives. The industry is conflicted in its commercial interests, while regulators would be both users and deployers of technology, such as in regtech, ${ }^{366}$ the use of Al to detect non-compliance and even predictive analytics. ${ }^{367}$ The dialogue around technology and institutional response must incorporate balanced representation of the competing interests in society. ${ }^{368}$

The development of $\mathrm{Al}$ is likely to be socially mediated through governance frameworks and initiatives from a variety of quarters, whether public, private or both in collaboration with each other. This larger context supports and reinforces our prediction in relation to technology's incremental impact on corporate law and governance development.

\section{Mainstream and Fringe DLT}

Although DLT can be used to construct a distributed economic space that rejects centralised institutions and hence any institution of authority, the social mediation of its potential may not culminate in fundamental/structural institutional change. We predict that certain efficiency qualities of DLT may be harnessed by mainstream corporations, and these can create increasingly new business processes and market experiences that are competitive and innovative. We are sceptical that the decentralised economic visions powered by DLT would become mainstream.

DLT is being experimentally used in business transformations in mainstream corporate sectors where efficiency gains are most likely, ${ }^{369}$ such as global supply chains, ${ }^{370}$ movements of international

\footnotetext{
${ }^{363}$ Brent Daniel Mittelstadt, Patrick Allo, Mariarosaria Taddeo, Sandra Wachter and Luciano Floridi, 'The Ethics of Algorithms: Mapping the Debate' (2016) Big Data and Society 1.

${ }^{364}$ Finck (2018) on co-regulation.

${ }^{365}$ The European Commission is proposing soft law in ethical standards and legal reform in product liability law for Al developers, see EU Commission Communication (2018). Further, see proposal for an international organisation for regulating Al in Olivia J Erdélyi and Judy Goldsmith, 'Regulating Artificial Intelligence: Proposal for a Global Solution' (2018) at https://par.nsf.gov/servlets/purl/10066933.

${ }^{366}$ This is experimented in financial regulation where regulators increasingly use Al to filter compliance reporting for concerning signals, see Dirk A Zetzsche, Ross P Buckley, Douglas J Arner and Janos Barberis, 'Regulating a Revolution: From Regulatory Sandboxes to Smart Regulation' (2017) 23 Fordham Journal of Corporate and Financial Law 31; also see concerns regarding technological judgments voiced in Nizan Geslevich Packin, 'Regtech, Compliance and Technology Judgment' (2018) 93 Chicago-Kent Law Review 193. ${ }^{367}$ The mechanics of predictive analytics and a discussion of pros and cons can be found in Eric Siegel, Predictive Analytics: The Power to Predict Who Will Click, Buy, Lie or Die (Chicester: John Wiley \& Sons 2013). ${ }^{368}$ Brownsword (2019), ch4.

${ }^{369}$ McKinsey \& Co, 'Blockchain Beyond the Hype: What is the Strategic Business Value?' (June 2018) at https://cybersolace.co.uk/CySol/wp-content/uploads/2018/06/McKinsey-paper-about-Blockchain-Myths.pdf. 370 Thomas Bocek, Bruno B. Rodrigues, Tim Strasser and Burkhard Stiller, 'Blockchains Everywhere - A Use-case of Blockchains in the Pharma Supply-Chain' (FIP/IEEE International Symposium on Integrated Network Management, 2017) at http://dl.ifip.org/db/conf/im/im2017exp/119.pdf; Sulkowski (2016).
} 
finance,${ }^{371}$ the internet-of-things economy ${ }^{372}$ and augmentation of virtual storage and access. ${ }^{373}$ However, the revolutionising nature of the distributed ledger as a database and coordinating platform should not be exaggerated as existing infrastructure is not that woeful or inefficient. Empirical research finds that conventional cloud storage and computing supported by Amazon, for example, is less expensive than DLT by a high factor of two. ${ }^{374}$ Further, existing coordination mechanisms in the corporate sector or even just the internal IT system in a large corporation may not be interoperable or upgradeable using DLT. ${ }^{375}$ An instructive observation is that even as 'fintech' payment companies, such as Ripple, bring market challenge to existing payment providers with their DLT offering, existing payment providers have not embarked on a full scale DLT conversion. Instead, we see significant consolidation amongst existing payment providers, integrating their coordination and communications mechanisms to improve complementary efficiencies and grow in scale, such as Visa's acquisition of Earthports and Payworks, ${ }^{376}$ Mastercard's acquisition of Vyse ${ }^{377}$ and Transfast ${ }^{378}$ and Ant Financial's acquisition of WorldFirst. ${ }^{379}$

We may see incremental adoption in terms of internal sharing of information and documentation, but extant technology such as Dropbox would equally facilitate this. We may see DLT being used for general meetings, such as in Santander as mentioned earlier, but one would have to see what difference it makes for participation and voting as compared to virtual meetings that can already be set up using Skype. We are also sceptical that DLT would facilitate radical or disruptive changes such as real-time accounting. The sharing of raw numbers with investors need not produce informed information for them or the securities marketplace. ${ }^{380}$ It may be argued that the existing EU/UK insider dealing laws which require companies to inform markets without delay when firms become aware of price-sensitive information ${ }^{381}$ are not that different from implementing 'real-time accounting'. However, this regulation applies only to information that becomes price-sensitive, and information can develop from being preliminary to price-sensitive over a course of formation. ${ }^{382}$

\footnotetext{
${ }^{371}$ Such as in international payments, led by Ripple's XRP DLT, and also other types of international finance such as trade finance, see Akgiray (2019), and clearing and settlement of financial instruments transactions see Avgouleas and Aggelos (2019).

372 Gianluca Salvotti, Leonardo Maria de Rossi and Nico Abbatemarco, 'A Structured Framework to Assess the Business Application Landscape ofBlockchain Technologies' (51st Hawaii International Conference on System Sciences 2018) at https://scholarspace.manoa.hawaii.edu/bitstream/10125/50328/1/paper0441.pdf.

373 Ibid. Jan Mendling et al, 'Blockchains for Business Process Management - Challenges and Opportunities' (2018) 9 ACM Transactions on Management Information Systems at https://arxiv.org/pdf/1704.03610.pdf.

374 Paul Rimba, An Binh Tran, Ingo Weber, Mark Staples, Alexander Ponomarev, Xiwei Xu, ‘Comparing Blockchain and Cloud Services for Business Process Execution' (2017) at https://www.researchgate.net/profile/Ingo Weber/publication/314213263 Comparing Blockchain and Clou d Services for Business Process Execution/links/5a273371aca2727dd883a2ee/Comparing-Blockchain-andCloud-Services-for-Business-Process-Execution.pdf.

375 McKinsey \& Co, above.

${ }^{376}$ At https://www.businesswire.com/news/home/20190507006199/en/Visa-Acquires-Control-Earthport; https://www.pymnts.com/news/partnerships-acquisitions/2019/visa-acquires-germany-based-payworks/. 377 https://www.pymnts.com/mastercard/2019/acquisition-vyze-pos-financing/.

378 https://www.paymentsjournal.com/mastercard-acquire-transfast-cross-border-business/.

379 'How Jack Ma can Turn British Coal into an Asian Gem' (Bloomberg, 14 Feb 2019) at https://www.bloomberg.com/opinion/articles/2019-02-14/jack-ma-s-ant-financial-buys-worldfirst-may-boostalibaba-growth.

380 Too much or unprocessed information does not necessarily 'inform' rational decision-making, see Richard E Mendales, "Collateralized Explosive Devices: Why Securities Regulation Failed To Prevent The CDO Meltdown, And How To Fix It" (2009) University of Illinois Law Review 1359.

${ }^{381}$ Art 17, EU Market Abuse Regulation applicable to the UK.

382 See Gelt l vaimler AG [2012] EUECJ C-19/11 (28 June 2012).
} 
Real-time accounting is more demanding than the EU/UK regulation and there is arguably no existing legal support for it.

It may be argued that the rise of peer-to-peer infrastructures such as DLT-enabled peer-to-peer energy trading or global wireless internet (in the example of Lungo discussed in Section A) may raise serious disruptive challenges to conventional business and ultimately, their governance. We predict that there will be social interest in engaging with alternative economic spaces but the fringe nature of such an economic space is likely to persist.

Truly decentralised DLT platforms can herald a different way of economic organisation, as flat peerto-peer structures can promote equality and inclusiveness in governance. ${ }^{383}$ Such alternative structures can generate a form of stakeholder capitalism, ${ }^{384}$ and challenge extant models of shareholder-centred capitalism. We are however sceptical of the contagious effect of these novel structures and governance, because their impact can be limited by the lack of scale of DLT-based businesses. Truly decentralised DLT-based business models face challenges in scalability as long as DLT developers hold stubbornly to a decentralised ethos of minimal governance and interference. The lack of 'organisation' of such infrastructure would likely confine it to precise use instead of growth in scale. ${ }^{385}$ However, niche innovations such as peer-to-peer energy trading and peer-to-peer computing storage or artwork sharing ${ }^{386}$ would likely have a dedicated following, as they tend to generate cult appeal. ${ }^{387}$

Further, regulators' stance on the growing 'initial coin' or 'token' offering market would also affect the rise of DLT-based development businesses. As heated activity in this marketplace has raised serious concerns of regulatory arbitrage, the position taken by the US SEC and CFTC has had a marked impact on the market for token finance. Developers may choose to exclude US investors, ${ }^{388}$ seek exemptions under existing securities rules, or conform to these rules. ${ }^{389}$ In this manner, token offerings would be shaped more like securities offerings and DLT business models would consequently be moulded to conform to the corporatized model.

In sum, the social mobilisation of DLT is likely to be driven by efficiency motivations on the part of conventional corporations. In so doing, cost may be driven down and consumers may remain happy with the extant productive economy. We see the cult appeal of fringe DLT-based crypto-economy businesses but decentralisation is not likely to be pursued by mainstream corporations. Further, DLTbased businesses may be inherently limited in scalability due to their lack of governance.

\section{Conclusion}

The rise of $\mathrm{Al}$ and DLT fascinates businesses and lawyers and some are concerned that as driverless cars may become mainstream in five years, major institutional change may be inevitable, such as in

\footnotetext{
${ }^{383} \mathrm{Eg}$. Fairmondo, which is a German-based marketplace for ethical trading, based on membership governance and one vote per member in a flattened decision-making hierarchy.

${ }^{384} \mathrm{R}$ Edward Freeman, "A Stakeholder Theory of the Modern Corporation" reproduced in Max BE Clarkson ed, The Corporation and Its Stakeholders (Univ of Toronto Press 1998) at 125.

${ }^{385}$ Earlier discussed in Section A under 'Radical/disruptive DLT'.

${ }^{386}$ For example, Resonate.is, a Berlin-based ethical music streaming company that aims to strike a fair distributive balance for the supply and demand sides of downloadable music. Another platform co-operative that aims to promote the distribution of high quality usable images while ensuring distributive fairness between the supply and demand sides is Stocksy United based in Canada.

${ }^{387}$ See https://cultbizztech.com/three-industries-likely-to-benefit-from-the-cryptocurrency-boom/.

388 'Why Token Issuers Exclude U.S. Investors' (Apr 2019) at https://www.ico.li/us-investors/.

389 'SEC Begins Green-Lighting Token Offerings' (July 2019) at https://news.bitcoin.com/sec-token-offerings/.
} 
corporate law and governance norms that have become cherished traditions over decades. This foreboding is premised upon the possibility of human agency being replaced and economic organisation being 'flattened' at various levels from top management to lower levels of skilled human capital. We argue that such institutional change would be navigated within a multi-factor theoretic framework that combines insights from institutional change, technological development and corporate law reform through history. This theoretical framework allows us to predict that technological change will be socially mediated and mobilised through an institutional framework towards three levels of possible changes: from incremental/facilitative changes, which we are already observing, to radical/disruptive and fundamental/structural changes which require heavy lifting and are more controversial. A highly automated and anti-hierarchical vision of the future may be some way away as our institutional framework still places human and social mediation of technology at the heart of institutional change. Institutional change is ultimately not technologydeterministic but institutionally-framed and anchored. Our predictions for change in corporate law and governance norms are nuanced based on the application of our framework. 